\title{
Exploring the Relationship Between Hardiness and Performance in Collegiate Baseball Players
}

Kevin R. Lou

West Virginia University, krl0018@mix.wvu.edu

Follow this and additional works at: https://researchrepository.wvu.edu/etd

Part of the Personality and Social Contexts Commons, and the Sports Studies Commons

\section{Recommended Citation}

Lou, Kevin R., "Exploring the Relationship Between Hardiness and Performance in Collegiate Baseball Players" (2020). Graduate Theses, Dissertations, and Problem Reports. 7972.

https://researchrepository.wvu.edu/etd/7972

This Thesis is protected by copyright and/or related rights. It has been brought to you by the The Research Repository @ WVU with permission from the rights-holder(s). You are free to use this Thesis in any way that is permitted by the copyright and related rights legislation that applies to your use. For other uses you must obtain permission from the rights-holder(s) directly, unless additional rights are indicated by a Creative Commons license in the record and/ or on the work itself. This Thesis has been accepted for inclusion in WVU Graduate Theses, Dissertations, and Problem Reports collection by an authorized administrator of The Research Repository @ WVU. For more information, please contact researchrepository@mail.wvu.edu. 
Exploring the Relationship Between Hardiness and Performance in Collegiate Baseball Players

Kevin R. Lou, B.S., B.A.

Thesis submitted

to the College of Physical Activity and Sport Sciences

at West Virginia University

Department of Sport Sciences

in partial fulfillment of the requirements for the degree of

Master of Science in

Sport, Exercise, and Performance Psychology

Scott Barnicle, Ph.D., Chair

Samuel Zizzi, Ed.D.

Justin Barnes, Ph.D.

Department of Sport Sciences

Morgantown, West Virginia

2020

Keywords: Hardiness, Personality, Objective Performance, Collegiate Baseball, Quantitative Copyright 2020 Kevin Lou 


\section{Abstract \\ Exploring the Relationship Between Hardiness and Performance in College Baseball Players}

\section{Kevin Lou}

The purpose of this study was to explore the influence of the individual personality characteristic of hardiness on trait anxiety and objective performance within NCAA Division I collegiate baseball players. An updated version of the PVS III-R was used to measure hardiness after a confirmatory factor analysis (CFA) was conducted. Of the total 389 players that participated, 171 met inclusion criteria requirements and were split into two groups - hitters $(N=94)$ and pitchers $(N=80)$ - to identify differences in skills and how sub-constructs of hardiness affected performance through a descriptive correlational prospective design. The results show significant moderating effects of commitment for pitchers that accounted for the majority of variance in the relationship between perception of trait anxiety intensity and left on base percentage (LOB\%) and wild pitches (WP). For hitters, significant moderating effects of control accounted for less variance in the relationship between perception of trait anxiety intensity on batting average on balls in play (BABIP) and double plays grounded into (GDP). The findings indicate there may be situational significance of hardiness' moderating effect on the relationship between trait anxiety and objective performance that may not be present until runners are on base. Practitioners could use these findings to target mental skills that could build up a pitcher's commitment or hitter's sense of control to moderate their performance within certain situations within collegiate baseball settings. Future studies could aim to replicate this study under normal NCAA collegiate baseball seasons when possible to corroborate situational findings and the utilization of updated PVS III-R scale.

Keywords: Hardiness, personality, objective performance, baseball, quantitative 


\section{Table of Contents}

Exploring the Relationship Between Hardiness and Performance in College Baseball Players .... 1

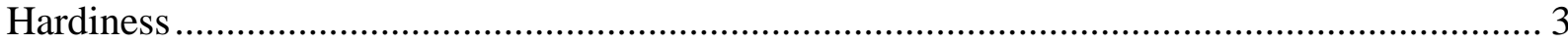

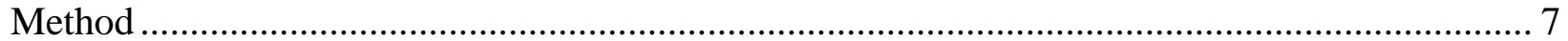

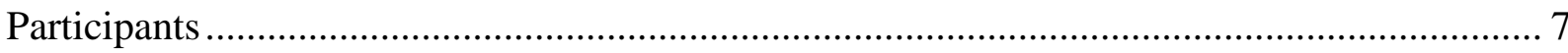

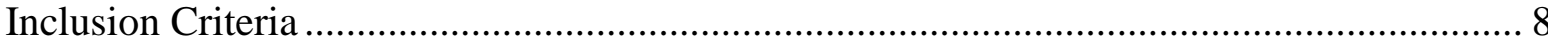

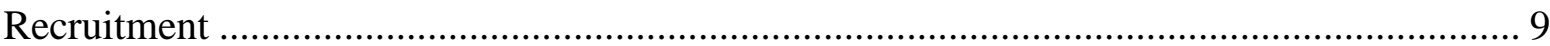

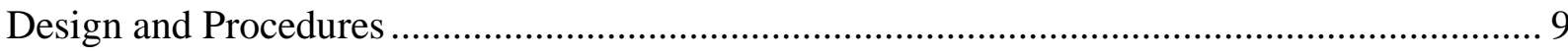

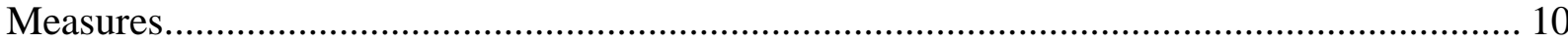

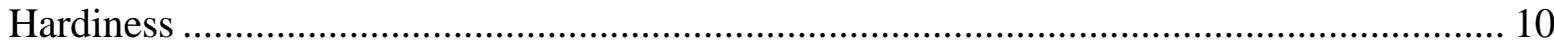

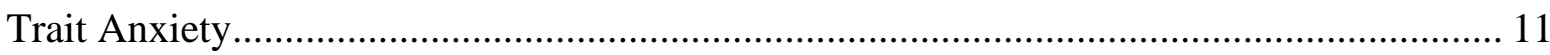

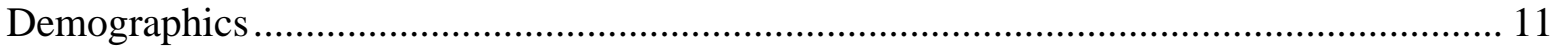

Objective Performance Baseball Statistics ............................................................... 12

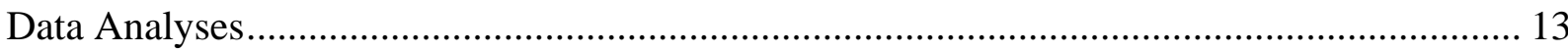

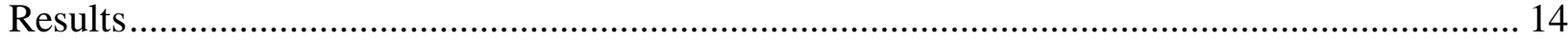

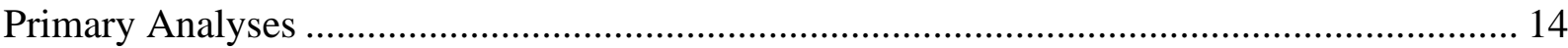

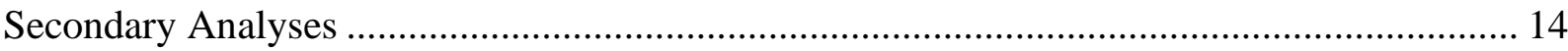

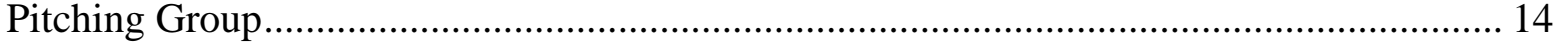

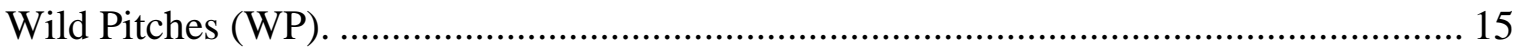

Left On-Base Percentage (LOB\%) . ................................................................... 16

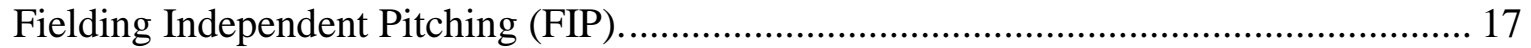

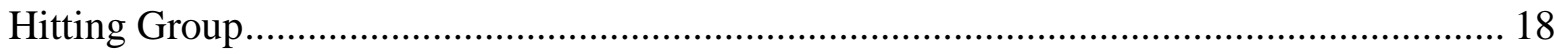

Batting Average on Balls In Play (BABIP)............................................................. 18

Grounding into Double Plays (GDP)........................................................................ 19

Weighted On-Base Average (wOBA). ................................................................... 19

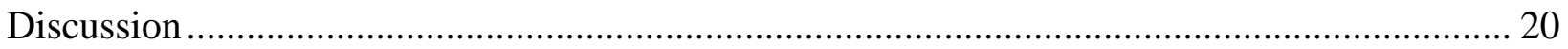

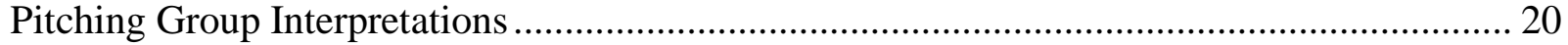

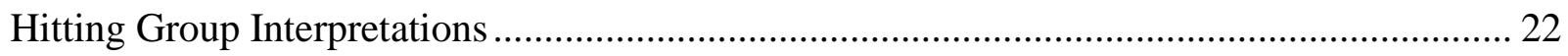

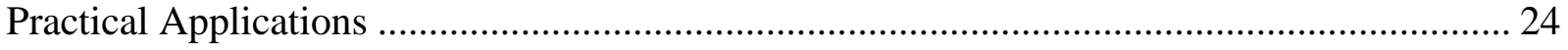

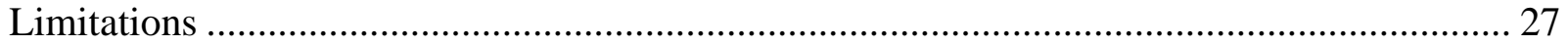

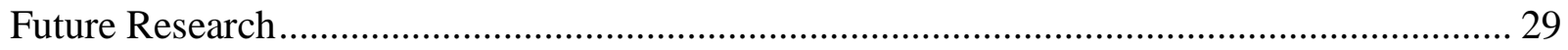




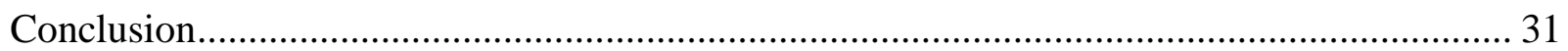

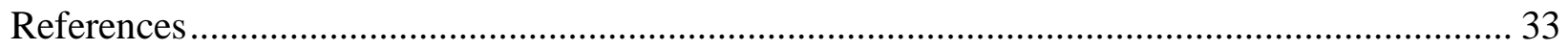

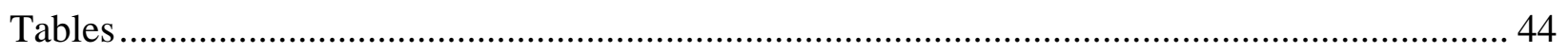

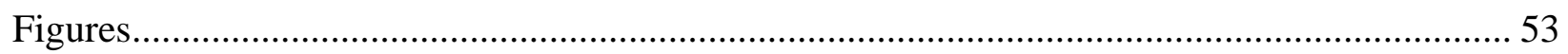

Appendix A: List of Hitting and Pitching Statistics and Formulas ......................................... 55

Appendix B: Hardiness Questionnaire - PVS III-R ....................................................... 57

Appendix C: Confirmatory Factor Analyses Procedure for Updated PVS III-R Scale ............... 58

Appendix D: Competitive Trait Anxiety Questionnaire - CTAI-2 ........................................ 61

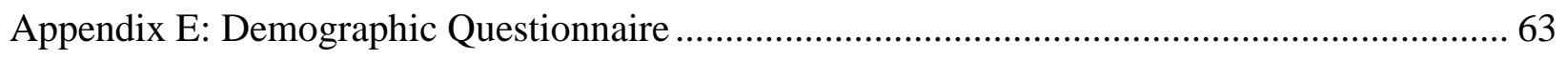

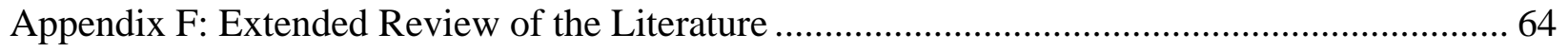

Individual Personality Characteristics Related to Competitiveness .................................... 65

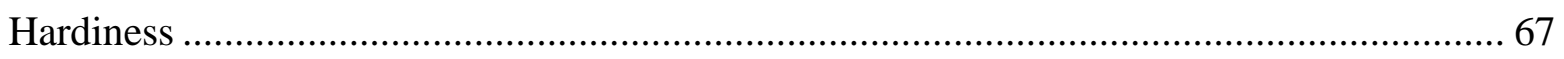

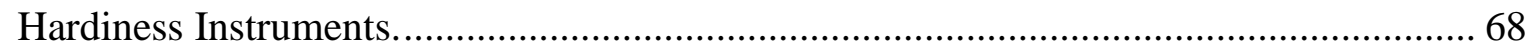

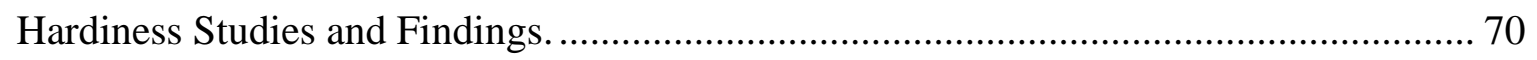

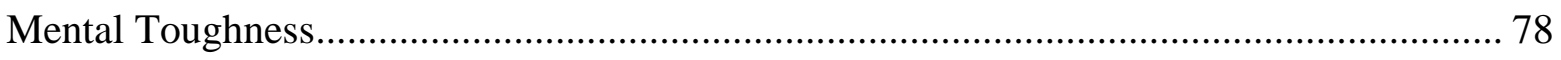

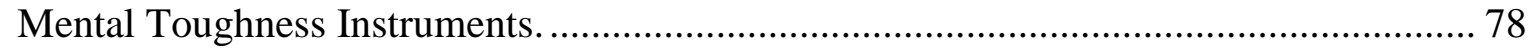

Mental Toughness Studies and Findings. ........................................................... 79

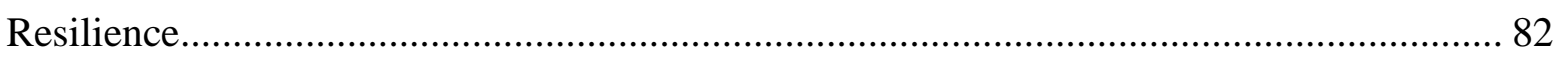

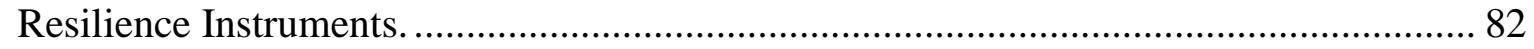

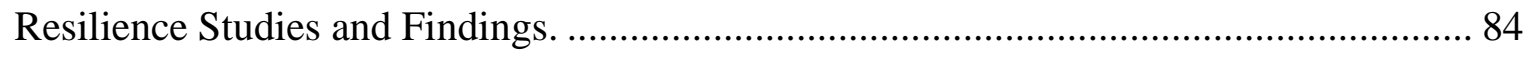

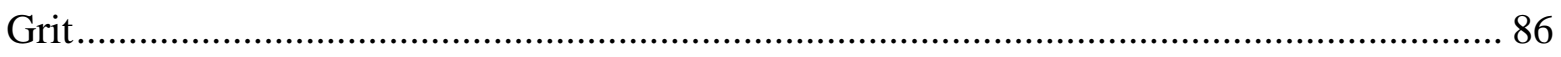

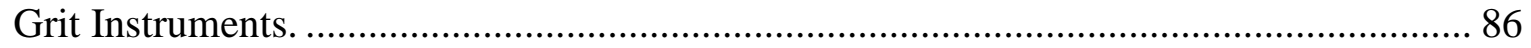

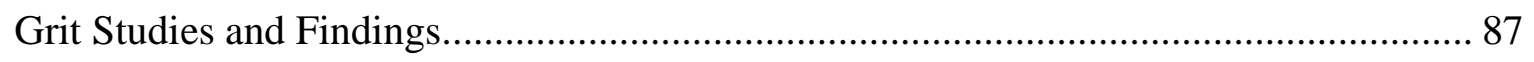

Summary of Competitiveness Characteristics................................................................. 90

Individual Competitiveness Characteristics and Objective Performance in Sport Settings..... 93

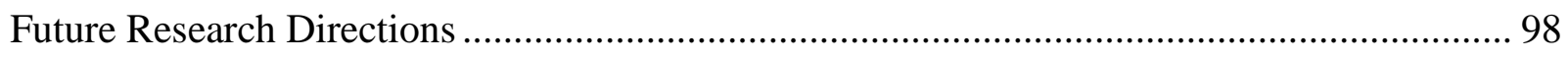

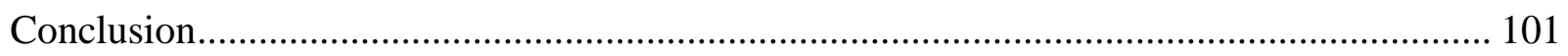




\section{Exploring the Relationship Between Hardiness and Performance in College Baseball Players}

In the 1950 s and 60s, sport personality was a widely popular field that captured researchers' curiosities with the idea that specific personality profiles could predict successful athletic performance (Allen et al., 2013). Early researchers used inventories such as the Eysenck Personality Inventory (EPI; Eysenck \& Eysenck, 1964) or the 16 Personality Factor (16PF) questionnaire developed by Cattell (1965) to attempt to predict personality profiles. Eventually, the field turned to the NEO Personality Inventory (NEO PI), developed by McCrae and Costa (1985) that combined elements of both the previous works of Cattell and Eysenck. The NEO PI measured five traits of personality, otherwise known by the acronym OCEAN, including openness, conscientiousness, extraversion, agreeableness, and neuroticism. Despite the NEO PI's improvements upon the $16 \mathrm{PF}$ and EPI, sport personality researchers still were not able to identify specific trait profiles that would determine future athletic performance.

Steady research continued through the mid-1980s when researchers realized that despite the abundance of studies which had investigated sport personality, there were no clear patterns of trait profiles that existed to predict performance (Morris, 2011). Some reasons for these inconclusive patterns could be explained by the limitations of global personality measures, restrictions of personality traits across temporal settings, and/or a reliance on personality profiles as a predictor of sport performance (Allen et al., 2017). However, after a twenty-year hiatus, sport-personality researchers have recently resumed interest in the field with a different approach that focuses on individual personality characteristics and singular trait-type personality rather than a full profile of traits (Roberts \& Woodman, 2017). One example of an individual personality characteristic that has gained support in the research is hardiness (Morris, 2011), while other characteristics such as trait anxiety (Spielberger, 1985) have increased in research interest as well. 
The revival of research within the sport personality field emphasizing individual personality characteristics demonstrates the still tantalizing possibility of forecasting athletic performance. Although the efforts to define specific personality traits across a generalized population have been inconclusive so far (Morris, 2011), the continued research in this field could yield athletes, coaches, and consultants valuable information. Furthermore, certain individual personality characteristics such as hardiness have found to be dynamic and malleable over time (McAdams \& Olson, 2010) and if practitioners could understand how to foster specific personality characteristics, then there may be significant advantages to be gained in performance (Roberts \& Woodman, 2017). For example, similarly to hardiness, trait anxiety helps influence appraisal and coping mechanisms and previous researchers have found that positively interpreting anxiety as facilitative can help athletes perform under pressure (Hanton \& Connaughton, 2002; Wadey \& Hanton, 2008). Future sport-personality research could help practitioners understand and tailor individual interventions and practices to each player to encourage an athlete's development (Allen \& Laborde, 2014) and facilitate their athletic performance.

In previous studies, conscientiousness had been linked to successful performance in collegiate athletes (Piedmont et al., 1999). Other researchers, such as Laborde et al. (2019), further examined this link in a recent mapping review by using a thematic analysis to map individual personality traits for sport performance onto its closest facet from the Big Five NEO. The 30 NEO-PI-R was used as a foundational framework because it captured fundamental components of human personality. One of the higher-order themes that the researchers identified was competitiveness. Within competitiveness, the thematic analysis used by the researchers identified grit, mental toughness, resilience, and hardiness as traits related to competitiveness. 
These traits were all linked to the Big-Five trait of conscientiousness (Laborde et al., 2019). While conscientiousness has been previously linked to successful performance, the relationship between athletic performance and these four traits is unclear and necessitates more research support to help forecast future performance.

Among the traits within the higher-order theme of competitiveness, grit, mental toughness, resilience, and hardiness may seem very similar and difficult to differentiate between (Price, 2019). However, researchers have faced difficulties conceptualizing the definitional construct of mental toughness (Gucciardi, 2017), have been limited by the narrow construct of resilience (Martin et al., 2015; Reivich et al., 2011), and have not been certain about grit and possible misinterpretations of statistical significance during initial studies (Crede et al., 2017). Therefore, hardiness may be the most viable construct of the four competitiveness constructs within the higher-order theme to be linked to athletic performance.

\section{Hardiness}

The construct of hardiness has come into focus for researchers as it meets the criteria for a personality characteristic of having both a theoretical base and allowing for developmental research (Morris, 2011). A theoretical basis of hardiness was developed by Kobasa (1979) in a landmark study where researchers investigated hardiness as a factor of whether employees of a telephone business company facing high levels of stress would fall ill. Those who reported high levels of stress and low levels of illness also reported higher levels of hardiness and had a stronger commitment to themselves, an attitude of commitment toward the environment, and an internal locus of control (Kobasa, 1979). Hardiness was thus defined by the three key factors of challenge, control, and commitment. Kobasa (1979) defined commitment as the willingness to engage oneself fully in whatever one is doing, control as the ability to influence the events of 
their experience, and challenge as the idea that change is exciting and essential to further development.

Among studies conducted on hardiness since Kobasa's work, extant research (Eschleman et al., 2010; Florian et al., 1995) has examined hardiness' influence in a range of sport and nonsport populations. The importance and potential of hardiness can be summed up in a metaanalytic study that included 180 studies investigating hardiness' antecedents and consequences across all domains. One finding from the study included that hardiness was positively correlated with job performance $(r=.17, \rho=.26, k=5, N=676)$ and school performance $(r=.21, \rho=.23, k=3$, $N=623$ ). Eschleman et al. (2010) concluded that hardiness is one of the better predictors of wellbeing in general populations compared to other health-oriented dispositions, such as self-esteem or locus of control. Specifically, in non-sport settings such as with military training, researchers have examined the influence of hardiness as a psychological resource in Israeli Defense Forces recruits (Florian et al., 1995). Researchers found that hardiness components helped individuals appraise combat training as less threatening, feel more capable of coping, and use more coping strategies. Commitment was positively associated with secondary appraisal $(r=.33)$, inversely related to threat appraisal $(r=-.31)$, and the use of distancing $(r=-.16)$ and emotion-focused coping $(r=-.30)$. Also, patterns of appraisal and coping related to higher levels of hardiness and led to better mental health. Researchers in non-sport settings have demonstrated hardiness' importance related to overall well-being and coping with stressful situations in military settings. The ability to improve hardiness to deal with stress and anxiety in the military could be related to similar situations found in sporting contexts.

One way that hardiness has been explored within sport is its influence on sport injury. Wadey et al. (2012) monitored 694 participants over the span of two years to observe injury 
occurrences. Researchers found that hardiness inversely correlated with injury occurrence, specifically as a participant's hardiness score increases, their risk of injury decreases (Wald test $=32.922, p<.001)$. Athletes who reported higher levels of hardiness experienced demanding athletic situations similarly to athletes who reported low levels of hardiness but appraised the situational demands as less stressful. The researchers hypothesized that this appraisal decreased significance of the stress response and possible future risk of injury. Individuals who reported higher levels of hardiness also transformed major life events from negative experiences into growth opportunities through appraisals, coping, and social support. Other studies with samples of 121 (Ford et al., 2000), 20 (Salim et al., 2016), and 10 (Wadey et al., 2012b) participants have also examined the relationship between hardiness and sport-injury.

Outside of sport-injury, hardiness has been researched across differing competition levels. Sheard and Golby (2010) found that athletes in both individual and team sports at higher competition levels scored higher in hardiness than those at subordinate levels specifically regarding the subcomponents of commitment and control. The researchers found a significant effect for commitment between competition levels $\left(p<.001, \eta_{p}^{2}=.05\right)$ which indicated that international competitors scored higher on commitment than national or club performers. There was also a significant effect for control $\left(p<.001, \eta_{p}^{2}=.04\right)$. This finding was also supported by later research by Thomas et al. (2013) (Cohen's $d=.6$ ) in the individual sport of motorcycle racing and by Golby and Sheard (2004) in rugby. Hardiness has also been examined by type of sport, specifically in high-school female-athletes (Devin et al., 2015). Researchers found that individual sport female athletes $(r=0.553, p<.05)$ were significantly better than team sport athletes $(r=0.435, p<.001)$ when reporting psychological hardiness and the three subcomponents of challenge, control, and commitment. Finally, researchers have also explored hardiness from a 
qualitative point of view as Thompson and Morris (2017) conducted an intervention to promote and develop hardiness within three elite rugby players. The researchers found that hardiness was an individual personality characteristic that could be developed even with elite level athletes and recommended similar future interventions.

Despite the previous research on hardiness, there has been a limited amount of research to re-examine the potential links between hardiness and objective performance. Some previous researchers have looked at hardiness as a predictor of flow in performance (Vealey \& Perritt, 2015) and included hardiness as a part of a psychological skills training program in swimmers (Sheard \& Golby, 2006). But still these researchers did not look specifically at the correlations between objective performance metrics and hardiness subscales. Other studies have recommended future research examining hardiness and anxiety interpretation and its relation to specific sport performance as a logical next step (Hanton et al., 2013), but there is a dearth of research in this regard.

One study that has investigated the interaction between objective performance and psychological constructs was a study conducted by Zizzi et al. (2003) where researchers examined the effect of emotional intelligence among college baseball players. The researchers used performance statistics from hitters and pitchers from NCAA Division I universities over a length of a season and found a modest link between performance and emotional intelligence in pitchers $(r(21)=.484, p<.05)$. Although this study does not specifically relate to hardiness, the methodological designs used in the study would be valuable to replicate in future studies attempting to identify possible associations between hardiness and objective performance measures that are widely available via baseball box scores. During the time since, baseball analytics has also become more nuanced and lends itself to more statistically available data that 
would support individual objective performance. Including these new statistics would be a superlative way to add significance to studies examining associations to objective performance in baseball.

Based on the need for continued research regarding the individual personality characteristic of hardiness, the present study aims to explore how hardiness may help athletes who experience anxiety perform, using objective performance metrics in NCAA Division I collegiate baseball players. This study's research questions include: (1) how does hardiness affect objective performance for pitchers and hitters; (2) is there a moderating relationship of hardiness on trait anxiety and performance; (3) are there differences in moderation effects between pitchers and hitters?

\section{Method}

\section{Participants}

Participants in this study included 389 male collegiate baseball players from 18 NCAA Division I baseball teams and 14 different conferences. The mean age of participants was 19.85 $(S D=1.24$, range $=18-23)$ with $54.2 \%$ of participants reported having some experience previously with sport psychology. The mean athletic class standing was $2.25(S D=1.12$, range $=$ 1-6) with example codes representing freshman as 1 , redshirt freshmen as 1.5 , and graduate students as 6 . In terms of race/ethnicity demographics, $76 \%(N=296)$ identified as White or Caucasian, $8 \%(N=30)$ identified as Black or African American, 7\% $(N=27)$ identified as Hispanic or Latino, 2\% $(N=7)$ identified as Asian or Asian-American, 3\% $(N=12)$ identified as biracial, and 4\% $(N=17)$ preferred not to provide information.

Of the 389 participants, 32 participants did not provide identifying information and therefore their questionnaire data was not able to be matched to their performance metrics. Fifty- 
eight of the rest of the 357 players who provided identifying information did not participate in any games during the 2020 shortened season. The remaining 299 players included 138 pitchers, 148 hitters, and 13 players who both pitched and hit at some point during the shortened season. Participants were separated into two different groups - hitters and pitchers - for the purpose of separating the tasks required of different players on the baseball field. However, it was possible that players were included in both the hitting and pitching groups if they met the inclusion criteria for both. After excluding pitchers and hitters who did not meet the inclusion criteria during the shortened season, the final number of participants in the hitting and pitching groups were 94 and 80 respectively for a total of 171 participants $(N=171)$ with three players qualifying for both groups.

\section{Inclusion Criteria}

In order to participate in this study, athletes had to: (1) be a listed member on the NCAA team roster; (2) provide provision of agreement to informed consent; and (3) be at least 18 years old. Inclusion criteria for hitters required at least two plate appearances per game and criteria for pitchers required at least two-thirds of an inning per outing. These inclusion criteria were modeled after a study that also measured objective performance in baseball (Zizzi et al., 2003).

Due to the shortened season, teams played between 13 to 21 games before the COVID19 global pandemic terminated the remainder of the NCAA Division I 2020 season. This is equivalent to approximately one-quarter to one-third of the total number of games that collegiate baseball seasons typically play. This range also includes more non-conference games played and fewer within-conference games than usual, as within-conference games are typically played during the middle or end of the collegiate baseball season. Using the lowest number of the games played, inclusion criteria were multiplied by 13 to reach the minimum number of at-bats or 
innings that hitters and pitchers needed to fall within the inclusion criteria. Therefore, to be included in the study, hitters must have at least 26 official at-bats to be included and pitchers must have pitched at least 8 innings to be included.

\section{Recruitment}

Participants were recruited via a convenience snowball sampling method. Head coaches from $280(94 \%)$ of the 299 total NCAA Division I baseball teams were contacted across all 32 conferences via email to ask if they were willing to let their athletes participate in the study during the offseason. Of the 280 teams that were contacted, $40(14 \%)$ teams and coaches responded and of those, $25(9 \%)$ teams agreed to participate. Additional information, including method of delivery of the questionnaires, the estimated time required of the athletes, and how to return the completed questionnaires to the researcher were provided to coaches who agreed to let their athletes participate. After agreeing to participate and sending out questionnaires, 18 (6\%) of teams returned completed surveys comprising of the final 18 teams included in this study.

Coaches and athletes who returned completed surveys were provided a follow-up report on personality and statistics from the shortened 2020 season with team-based findings to help understand the current team's personality and performance.

\section{Design and Procedures}

A prospective descriptive correlational design was utilized in this study, in which participant questionnaire data was matched with publicly available objective performance statistics from the 2020 COVID-19 shortened NCAA Division I baseball season. This approach modeled the descriptive correlational design utilized in the study by Zizzi et al. (2003) to explore objective performance among baseball players. 
After obtaining institutional review board (IRB) approval, head coaches of 280 NCAA Division I baseball teams were contacted via email. Upon agreement, informed consents forms and questionnaires were distributed either online, through a Qualtrics link, or via paper and pencil surveys sent in the mail, depending upon each team's preference. In both scenarios, the researchers were not present during the administration or completion of the surveys, but a member of the team or a coach acted as a conduit and was given instructions to administer, collect, and send the questionnaires back. PVS III-R and CTAI-2 measures were counterbalanced before being distributed. Each completed questionnaire was given an anonymous code in order to de-identify the data after matching to each athlete's performance data. Performance statistics were tracked through each respective baseball team's website, which were made publicly accessible by the team after an official scorer tracked each game over the span of the season.

\section{Measures}

\section{Hardiness}

Hardiness was originally measured using the Personal Views Survey III-R (PVS III-R), an 18 -item scale with six items pertaining to each of the three sub-scales of challenge, commitment, and control (Maddi et al., 2006). PVS III-R utilized a four-point Likert scale ranging from 0 (not at all true) to 3 (very true). An example item was "Trying your best at what you do usually pays off in the end." The PVS III-R had an internal consistency coefficient alpha of 0.80 (Maddi et al., 2006) and strong positive inter-correlations were reported between the three subcomponents of hardiness and the total hardiness scale (Maddi, 2012). For more details, please reference Appendix B. After reliability statistics on the collected responses revealed poor loadings onto the three sub-scales of hardiness, a confirmatory factor analysis (CFA) was conducted. This CFA led to the use of an updated PVS III-R scale which included just nine of 
the original 18 items with three items for each subscale. The composite reliability estimate for the revised nine-item PVS-III R was 0.76. For more details on the confirmatory factor analysis process, please reference Appendix C.

\section{Trait Anxiety}

Trait anxiety was measured using the Competitive Trait Anxiety Inventory-2 (CTAI-2; Parfitt et al., 1990). This scale was modified from the Competitive State Anxiety Inventory-2 (Martens et al., 1990) by editing instructions that originally asked individuals to indicate how they felt at the current moment to how they usually felt right before competition to create a trait measure. The 27-item scale consists of three subscales with nine questions for somatic anxiety, cognitive anxiety, and self-confidence and one question reverse-scored within the somatic anxiety subscale. The scale is separated into two sections measuring intensity and interpretation of trait anxiety. The first section measured the perceived intensity of pre-competition anxiety and was measured on a four-point Likert scale ranging from 1 (not at all) to 4 (very much so). The second section of the scale measured whether the athlete interpreted the anxiety as facilitative or debilitative and was measured on a seven-point Likert scale ranging from -3 (very negative or debilitative) to 3 (very positive or facilitative). An example item was "I am concerned I may not do as well in this competition as I could." The CTAI-2 has a reported Cronbach's alpha value of 0.83 (Perry \& Williams, 1998). For more details, please reference Appendix D.

\section{Demographics}

Demographic information collected included each participant's name, age, ethnicity/race, college/university, position(s) played, current jersey number, previous experience with sport psychology, if any, and other NCAA DI sports played, if any. Participant names, college/university attended, and current jersey number were used as identifying information to 
link objective performance data to questionnaires completed by specific players. For more details on instructions and layout of demographic questionnaire, please reference Appendix E.

\section{Objective Performance Baseball Statistics}

In addition to objective baseball performance statistics examined in a previous study

(Zizzi et al., 2003), this study included newer baseball objective performance data that are being commonly used to make analytical decisions in professional baseball organizations. This study tracked total hits, total doubles, total walks, total double plays grounded into, and total strikeouts for hitters as well as total earned runs, total walks, total hits allowed, total strikeouts, and total wild pitches for pitchers to corroborate and compare to previously conducted studies (Zizzi et al., 2003). In addition to those statistics, this study also calculated the following baseball statistics: On-Base Percentage Plus Slugging (OPS), Weighted On-Base Average (wOBA), Batting Average on Balls in Play (BABIP) for hitters and Walks Hits per Innings Pitched (WHIP), Fielding Independent Pitching (FIP), and Left On-Base Percentage (LOB\%) for pitchers. Each of these statistics were averaged over the span of the 2020 shortened season. For more detailed information and formulas to calculate each statistic, please reference Appendix A. All information about what these statistics mean and how to calculate them was found on FanGraphs' website (Slowinski, 2010). These statistics were chosen based on the feasibility of calculation using the statistics given by the game-performance results found on publicly accessible team websites. The inclusion of these statistics also helps add to the range of objective performance metrics measured in existing sport psychology literature. With the increased use of statistics such as FIP and BABIP in professional baseball organization's decision making, inclusion of these statistics in research adds to the relevance of extant research. 


\section{Data Analyses}

Responses to questionnaires that were completed via paper and pencil were entered through a double-data entry system, once by the researcher and once by a research assistant, in order to minimize data entry errors. Responses to questionnaires that were completed through Qualtrics were downloaded and aggregated together with paper and pencil responses after completion of double-data entry system. Data collected from publicly available statistics on team websites were entered for players who had provided identifying information and consented to be included in the study. Questionnaire data were then linked to available performance data and questionnaire and demographic information were de-identified and separated based on player group. After, researchers used the previously-decided inclusion criteria of at least 26 at-bats for hitters and 8 innings for pitchers to identify which players met the inclusion criteria.

Using the updated 9-item scale for the PVS III-based on CFA (Appendix C), data analyses were conducted using the updated PVS III-R scale, CTAI-2 Intensity scale, CTAI-2 Interpretation scale, and selected objective performance statistics collected from the 2020 shortened baseball season. Pearson correlations were conducted in SPSS and moderation analyses were conducted using the PROCESS add-on in SPSS (Hayes, 2012, 2013). Pearson correlation analyses were conducted for all variables within both the hardiness and trait anxiety subscales, on both pitchers and hitters' objective performance statistics. Following the Pearson correlations, moderation analyses were then conducted to identify the moderating role of players' hardiness on the relationship between their trait anxiety and measures of their performance. During moderation analyses, the Johnson-Neyman technique was used to probe significant interactions beyond initial conditional effects if initial significance was obtained. This technique 
was used to supersede the arbitrary pick-a-point approach at the $16^{\text {th }}, 50^{\text {th }}$, and $84^{\text {th }}$ percentiles used in conditional effects commonly conducted in PROCESS (Hayes, 2013).

\section{Results}

\section{Primary Analyses}

Descriptive statistics for all variables across all groups are presented in Table 1. Correlations among primary variables are presented in Tables 2 and 3 for pitchers and hitters, respectively. Overall, pitchers showed evidence of mostly weak to moderate correlations between personality characteristics and objective performance statistics. Hitters, similarly, showed evidence of mostly weak to moderate correlations between personality characteristics and objective performance statistics.

\section{Secondary Analyses}

Moderation analyses were conducted to examine the conditional effects of commitment in relation to pitchers and control in relation to hitters. These analyses did not include challenge as it had the weakest loading during the CFA and has previously been questioned as strong of a sub-construct as commitment and control (Sheard \& Golby, 2006). Full moderation analyses data tables for pitchers and hitters are presented in Tables 4 and 6 respectively, and conditional effects using Johnson-Neyman probing technique for pitchers and hitters are presented on Tables 5 and 7 respectively. Analysis of objective performance metrics were further narrowed down to examine the moderating effect of commitment on newer objective performance statistics for the pitching group.

\section{Pitching Group}

For pitchers, examination of the moderating effect of commitment on the relations between trait anxiety intensity and objective performance statistics revealed that for both wild 
pitches and left on-base percentage, all three sub-scales of trait anxiety intensity were significantly moderated by commitment while fielding independent pitching was not significantly moderated by commitment.

Wild Pitches (WP). For wild pitches, cognitive anxiety intensity, $\beta=0.05, S E=0.01, t=$ 3.53, $p<0.05,95 \%$ CI [0.02, 0.07], somatic anxiety intensity, $\beta=0.04, S E=0.01, t=3.18, p<$ $0.05,95 \% \mathrm{CI}[0.02,0.07]$, and self-confidence intensity, $\beta=0.03, S E=0.01, t=2.94, p<0.05$, 95\% CI $[0.01,0.05]$ were all significantly moderated by commitment. A pitcher would like to limit the number of wild pitches thrown as wild pitches occur while runners are on-base and usually indicates the pitcher threw a ball that allowed the runner to advance to the next base. The Johnson-Neyman technique indicated that for pitchers with scores above 6.37 - or above the $54^{\text {th }}$ percentile - on commitment, a significant positive relationship was found between pitcher's cognitive anxiety intensity and number of WP thrown for pitchers scoring higher on commitment, $\beta=0.05, S E=0.03, t=1.99, p<0.05,95 \%$ CI $[0.00,0.10]$. These findings indicate that pitchers with higher levels of commitment threw fewer wild pitches when perceiving lower intensities of their cognitive anxiety. Commitment explained more than half of the variance in wild pitches thrown $\left(R^{2}=0.24, \Delta R^{2}=0.13\right)$.

For somatic anxiety intensity, the Johnson-Neyman technique indicated that for pitchers with scores above 7.05 - or above the $73^{\text {rd }}$ percentile - on commitment, a significant positive relationship was found between pitchers' somatic anxiety intensity and number of wild pitches thrown for pitchers scoring high on commitment, $\beta=0.06, S E=0.03, t=1.99, p<0.05,95 \% \mathrm{CI}$ $[0.00,0.12]$. These findings indicate that pitchers with higher levels of commitment threw fewer wild pitches when perceiving lower intensities of their somatic anxiety. Commitment explained more than half of the variance in wild pitches thrown $\left(R^{2}=0.20, \Delta R^{2}=0.11\right)$. 
For self-confidence intensity, the Johnson-Neyman technique indicated that for pitchers with scores above 7.13 - or above the $73^{\text {rd }}$ percentile - on commitment, a significant positive relationship was found between pitcher's self-confidence intensity and number of wild pitches thrown for pitchers scoring high on commitment, $\beta=0.04, S E=0.02, t=1.99, p<0.05,95 \% \mathrm{CI}$ $[0.00,0.09]$. These findings indicate that pitchers with higher levels of commitment threw fewer wild pitches despite perceiving low intensities of their self-confidence. Commitment explained approximately half of the variance in wild pitches thrown $\left(R^{2}=0.18, \Delta R^{2}=0.09\right)$.

Left On-Base Percentage (LOB\% ). Similarly, for LOB\%, cognitive anxiety intensity, $\beta$ $=-0.004, S E=0.001, t=-2.95, p<0.05,95 \% \mathrm{CI}[-0.006,-0.001]$, somatic anxiety intensity, $\beta=$ $-0.003, S E=0.001, t=-2.72, p<0.05,95 \% \mathrm{CI}[-0.006,-0.001]$, and self-confidence intensity, $\beta$ $=-0.002, S E=0.001, t=-2.10, p<0.05,95 \% \mathrm{CI}[-0.004,0.000]$ were all significantly moderated by commitment. A higher LOB\% identifies that a pitcher was able to prevent runners that were allowed on base from scoring. The Johnson-Neyman technique indicated that for pitchers with scores above 8.78 - or above the $88^{\text {th }}$ percentile - on commitment, a significant inverse relationship was found between pitchers' cognitive anxiety intensity and LOB\% for pitchers scoring high on commitment, $\beta=-0.008, S E=0.004, t=-1.99, p<0.05,95 \% \mathrm{CI}[-0.02$, 0.00]. These findings indicate that pitchers with higher levels of commitment had higher LOB\% when perceiving lower intensities of their cognitive anxiety.

Conversely, the Johnson-Neyman technique also indicated that for pitchers with scores below 5.06 - or below the $27^{\text {th }}$ percentile - on commitment, a significant positive relationship was found between pitcher's cognitive anxiety intensity and LOB\% for pitchers scoring low on commitment, $\beta=0.005, S E=0.003, t=1.99, p<0.05,95 \%$ CI $[0.00,0.01]$. These findings indicate that pitchers with lower levels of commitment had lower LOB\% when perceiving lower 
intensities of their cognitive anxiety. Commitment explained the majority of the variance in $\operatorname{LOB} \%\left(R^{2}=0.12, \Delta R^{2}=0.10\right)$.

For somatic anxiety intensity, the Johnson-Neyman technique indicated that for pitchers with scores above 8.86 - or above the $88^{\text {th }}$ percentile - on commitment, a significant inverse relationship was found between pitcher's somatic anxiety intensity and LOB\% for pitchers scoring high on commitment, $\beta=-0.008, S E=0.004, t=-1.99, p<0.05,95 \%$ CI [-0.02, 0.00]. These findings indicate that pitchers with higher levels of commitment had higher LOB\% when perceiving lower intensities of their somatic anxiety. Commitment explained the majority of the variance in $\mathrm{LOB} \%\left(R^{2}=0.10, \Delta R^{2}=0.09\right)$.

For self-confidence intensity, the Johnson-Neyman technique indicated that for pitchers with scores below 4.01 - or below the $8^{\text {th }}$ percentile - on commitment, a significant positive relationship was found between pitcher's self-confidence intensity and LOB\% for pitchers scoring low on commitment, $\beta=0.005, S E=0.002, t=1.99, p<0.05,95 \%$ CI [0.00, 0.01]. These findings indicate that pitchers with lower levels of commitment had lower LOB\% when perceiving lower intensities of self-confidence, however this is limited to a small percentile and group of pitchers who scored below this low percentile. Commitment explained the majority of the variance in $\operatorname{LOB} \%\left(R^{2}=0.07, \Delta R^{2}=0.06\right)$.

Fielding Independent Pitching (FIP). For FIP, cognitive anxiety intensity, $\beta=0.007$, $S E=0.02, t=0.45, p>0.05,95 \% \mathrm{CI}[-0.03,0.04]$, somatic anxiety intensity, $\beta=0.005, S E=$ $0.02, t=0.33, p>0.05,95 \%$ CI [-0.03, 0.04], and self-confidence intensity, $\beta=-0.004, S E=$ $0.01, t=-0.33, p>0.05,95 \% \mathrm{CI}[-0.03,0.02]$ were all not significantly moderated by commitment. A pitcher's FIP identifies a pitcher's ability to prevent runs independent of their defense. Commitment explained minimal variance in the relationships for cognitive anxiety 
intensity $\left(R^{2}=0.12, \Delta R^{2}=0.002\right)$, somatic anxiety intensity $\left(R^{2}=0.12, \Delta R^{2}=0.001\right)$, and selfconfidence intensity $\left(R^{2}=0.12, \Delta R^{2}=0.001\right)$ and FIP.

\section{Hitting Group}

Objective performance statistical analyses for hitters were further narrowed down to examine the moderating effect of control on the relationship between trait anxiety intensity on newer objective performance statistics. Examination of the moderating effects of control revealed that control significantly moderated the relationship between somatic anxiety intensity and batting average on balls in play and the relationship between self-confidence intensity and grounding into double plays.

Batting Average on Balls In Play (BABIP). For BABIP, cognitive anxiety intensity, $\beta=$ 0.001, $S E=0.001, t=1.03, p>0.05,95 \% \mathrm{CI}[-0.001,0.004]$ and self-confidence intensity, $\beta=$ $0.001, S E=0.001, t=0.96, p>0.05,95 \% \mathrm{CI}[-0.001,0.002]$ were both not significantly moderated by control. However, somatic anxiety intensity, $\beta=0.003, S E=0.001, t=2.15, p<$ $0.05,95 \%$ CI $[0.00,0.006]$ was significantly moderated by control on somatic anxiety intensity's effect on a hitter's BABIP. Similar to batting average, higher BABIPs would indicate better objective performance for hitters. The Johnson-Neyman technique indicated that for hitters with scores below 5.50 - or below the $44^{\text {th }}$ percentile - on control, a significant inverse relationship was found between hitter's somatic anxiety intensity and BABIP for hitters scoring lower on control, $\beta=-0.004, S E=0.002, t=-1.99, p<0.05,95 \% \mathrm{CI}[-0.09,0.00]$. These findings indicate that hitters with lower levels of control had lower BABIPs when perceiving high intensities of their somatic anxiety. Control explained half of the variance in the relationship between somatic anxiety intensity and $\mathrm{BABIP}\left(R^{2}=0.09, \Delta R^{2}=0.05\right)$, but minimally for cognitive anxiety intensity $\left(R^{2}=0.05, \Delta R^{2}=0.01\right)$ and self-confidence intensity $\left(R^{2}=0.04, \Delta R^{2}=0.01\right)$. 
Grounding into Double Plays (GDP). For number of double plays grounded into, cognitive anxiety intensity, $\beta=-0.004, S E=0.01, t=-0.36, p>0.05,95 \%$ CI $[-0.03, .02]$ and somatic anxiety intensity, $\beta=-0.02, S E=0.01, t=-1.07, p>0.05,95 \%$ CI $[-0.04,0.01]$ were both not significantly moderated by control. However, self-confidence intensity, $\beta=-0.01, S E=$ $0.007, t=-2.16, p<0.05,95 \%$ CI $[-0.03,-0.001]$ was significantly moderated by control on selfconfidence intensity's effect on the number of double plays grounded into. Hitters ideally would aim to avoid hitting into double plays and grounding into less double plays would represent a better hitter's performance. The Johnson-Neyman technique indicated that for hitters with scores above 5.93 - or above the $43^{\text {rd }}$ percentile - on control, a significant inverse relationship was found between hitter's self-confidence intensity and number of double plays grounded into for hitters scoring high on control, $\beta=-0.03, S E=0.01, t=-1.99, p<0.05,95 \%$ CI $[-0.05,0.00]$. These findings indicate that hitters with higher levels of control grounded into less double plays when perceiving high intensities of their self-confidence. Control explained one-quarter of the variance in the relationship between self-confidence intensity and number of double plays grounded into $\left(R^{2}=0.16, \Delta R^{2}=0.04\right)$, but minimally for cognitive anxiety intensity $\left(R^{2}=0.08, \Delta R^{2}=0.001\right)$ and somatic anxiety intensity $\left(R^{2}=0.09, \Delta R^{2}=0.01\right)$ and number of double plays grounded into.

Weighted On-Base Average (wOBA). For wOBA, cognitive anxiety intensity, $\beta=$ $0.000, S E=0.001, t=0.24, p>0.05,95 \% \mathrm{CI}[-0.002,0.003]$, somatic anxiety intensity, $\beta=$ 0.002, $S E=0.001, t=1.31, p>0.05,95 \% \mathrm{CI}[-0.001,0.005]$, and self-confidence intensity, $\beta=$ $0.001, S E=0.001, t=1.66, p>0.05,95 \%$ CI $[0.000,0.003]$ were all not significantly moderated by commitment. While batting average weighs all hits the same, wOBA weights home runs higher than singles and higher wOBA indicate better hitter performance. Control explained approximately one-third of the variance in the relationship between somatic anxiety intensity $\left(R^{2}\right.$ 
$\left.=0.06, \Delta R^{2}=0.02\right)$ and self-confidence intensity and wOBA $\left(R^{2}=0.08, \Delta R^{2}=0.03\right)$, but minimally for cognitive anxiety intensity and wOBA $\left(R^{2}=0.04, \Delta R^{2}=0.001\right)$.

\section{Discussion}

While there have been a several studies that have examined the effect of competitive anxiety on sport performance (Lagos, 2008) and baseball specifically (Chang \& Torres, 2019; Chen et al., 2019; Han, 2014; Strack, 2003), very few studies have examined the influence of personality and specifically hardiness on a player's ability to perform in the presence of competitive anxiety in baseball. The current study provides contributions to further understand the influence of hardiness on objective performance statistics in the presence of competitive anxiety intensity within a collegiate baseball setting. This study also found similar objective performance results to previous correlational investigations found in the Zizzi et al. (2003) study.

\section{Pitching Group Interpretations}

It is important to interpret the results of this study within the context that each objective performance baseball statistics indicates. Among the moderating effects for pitchers, both statistically significant effects suggest that there were situational or contextual effects of commitment which may help a pitcher's performance when perceiving high intensities of trait anxiety. Both left on base percentage and wild pitches are statistics that require the presence of runners on base and typically are considered to be higher stress or anxiety-provoking situations during games (Chang \& Torres, 2019). Pitchers even change their stance on the mound from a windup position to a stretch position that is quicker and combats the likelihood or ability of a runner to steal a base against that pitcher. Pitchers may perceive their anxiety to be more intense during these situations and the data suggested that commitment moderated the effect of a pitcher's perception of the intensity of anxiety and led to less wild pitches and higher left on-base 
percentages. These effects were not found to be the case for fielding independent pitching. These results may indicate a more situational or state-like effect of the moderating effect of commitment on a pitcher's objective performance. As recommended by a researcher via interview from a previous study (Zizzi et al., 2003), a useful area of future focus was situational effects that allowed pitchers to reflect on their own internal state and how it affects their performance. The results of this study seem to corroborate the situational moderating effects of commitment on a pitcher's ability to throw fewer wild pitches and leave runners on base compared to fielding independent pitching, which is not as situational. Practitioners could use these findings to focus their interventions to improve a pitcher's commitment during specific situations within baseball that might lead to higher anxiety moments to help pitchers increase their performance.

The coefficients of determination $\left(\mathrm{R}^{2}\right)$ for this groups' moderation analyses indicate the amount of variance accounted for in pitching performance by trait anxiety intensity. For both left on-base percentage and wild pitches, the amount of $\mathrm{R}^{2}$ change that was accounted for by the moderating variable of commitment was at least half and in the case of left on-base percentage, commitment accounted for the majority of the variance between the relationship between trait anxiety and left on-base percentage. Although the overall $\mathrm{R}^{2}$ may be considered small, at higher levels of competitive sport, physical abilities become more comparable and small increases in mental skills or personality could lead to larger influences in performance outcomes (Zizzi et al., 2003). The $\mathrm{R}^{2}$ change values for both situational statistics of wild pitches and left on base percentage suggest that a large amount of variance on a pitcher's performance during on-base situations could be influenced by a pitcher's higher level of commitment with runners on base in the presence of trait anxiety. Especially in regard to LOB\%, the majority of variance accounted 
for by commitment suggests that improving a pitcher's level of commitment could account for the majority of improvement in a pitcher's LOB\% and could be a focus for practitioners.

\section{Hitting Group Interpretations}

In comparison to the pitcher group findings, the hitter group moderation analyses of the subscale of control were mostly non-significant with the exception of one situational statistic and one non-situational statistic. These findings are particularly interesting as one significant finding was related to self-confidence while the other was somatic anxiety. In a previous study conducted by Davis and Sime (2005) within baseball, the researchers recommended sport psychologists to focus on improving self-confidence rather than reducing anxiety to help performance. However, if practitioners wanted to help baseball players address their anxiety, the findings in this study seem to provide some evidence that this could be done through development of their personality and particular subscales of hardiness. The findings indicate that practitioners could both try to improve self-confidence and address anxiety through improvement of control while for pitchers reduction of anxiety could be achieved through improvement of commitment to increase performance. Different positions require different skills from players and the findings allow practitioners to potentially target these differences in multiple ways.

Similar to wild pitches for pitchers, grounding into double plays for hitters require runners on base and is also considered a negative performance statistic. Typically, grounding into double plays is not seen to be in the control of a hitter as various factors by the opposing team or umpire could affect whether the hitter actually hits into a double play and require that there are fewer than two outs as well (Slowinksi, 2010). GDP situations may elicit higher feelings of self-confidence as there is a runner on base that makes it easier for the hitter to score the runner on base to help the team rather than having to a hit a home run on their own (George, 
1994). As a situational statistic, the results from this study indicate that hitters who believe these situations with runners on base are more in their control and perceive high levels of selfconfidence will ground into fewer double plays and therefore allow their team to continue to hit. Unfortunately, this statistic does not give any insight to what type of other results the hitter may have hit into such as a home run or fly-out to right field. It does suggest that high intensities of self-confidence paired with high levels of control could lead to less double plays grounded into which would allow the team more opportunities to continue hitting and score runs.

The non-situational statistic that was found to be significant was a hitters' batting average on balls in play (BABIP) which has been discussed to be more in control of a hitter than a pitcher (Slowinski, 2010). It is understood that a hitter has control over how often they decide to put the ball in play and how hard they hit it, but not if it actually ends up being a hit due to the defense or luck. When considering the results in this study, it was demonstrated that when hitters had lower feelings of control, they had lower BABIPs and higher perceptions of their somatic anxiety. Practitioners and consultants in applied sport and exercise psychology may explore ways to increase a hitter's perception of the situation being within their control through cognitive re-appraisal (De Castella et al., 2013). This may help increase hitter's BABIP when they perceive their somatic anxiety to be high which corroborates results found in a previous study exploring competitive anxiety in baseball players (Strack, 2003). There were no significant differences found for weighted on base average perhaps indicating that hitters do not have much control over their weighted on-base percentage which includes contributions out of their control like being hit by pitches or walks.

The coefficients of determination $\left(\mathrm{R}^{2}\right)$ for this groups' moderation analyses indicate the amount of variance accounted for in hitting performance by trait anxiety intensity. For the 
majority of moderation relationships, the amount of $\mathrm{R}^{2}$ that was accounted for by the moderating effect of control was very small. However, the relationship between somatic anxiety intensity and BABIP was accounted for by the moderating variable of control was over half. In the relationship between self-confidence intensity and grounding into double plays, control accounted for just one-quarter of the variance despite the largest $\mathrm{R}^{2}$ value among hitter group moderating effects. Although the $\mathrm{R}^{2}$ change values for hitters do not explain for as much or as many of the trait anxiety variables as pitchers, a situational statistic with runners on base was still significant moderated by control as well as a non-situational statistic which was not found in pitchers and corroborates hunches by baseball analysts (Slowinski, 2010).

\section{Practical Applications}

A few practical contributions can be taken from this study for consultants or practitioners when working with baseball players. First, with the findings that pitchers are largely moderated by their level of commitment during pressure or anxious situations with runners on base, practitioners could aim to increase a pitcher's ability to reframe the intensity of the anxiety that is perceived by focusing on their commitment towards the next pitch. Reminding pitchers that during situations with runners on base, the data shows that having a higher level of commitment in the pitches that they are throwing could lead to higher LOB\% and less wild pitches even if they feel a high intensity of cognitive or somatic anxiety or a low feeling of self-confidence. Using the sub-construct definition of commitment, one's "ability to persist in whatever one is doing, even when stress rises to precarious levels" (Kobasa, 1979), practitioners could help pitchers re-focus their commitment through imagery or breathing when they feel they are in those situations. As found in a previous study that identified that breathing helped decrease heart rate variability and improved performance on the golf course (Lagos, 2008), similar focus on the 
breath within a batter's routine could help refocus the pitcher's sense of commitment. These situational statistics that were found to be significant in this study could be specific situations that practitioners focus on with pitches and focus on reframing pitchers to focus on their commitment instead of the high intensity of their anxiety during those situations. Also, the results show that regardless of the type of anxiety, commitment explains the majority of moderating effects which indicates that commitment is the driving force of the improvement in these situational statistics and provides a practical avenue to address with mental skills.

Hitters do not seem to have as large of a moderating effect in as many situational settings, but control seems to moderate some overall performance but not to the extent found in pitchers. This finding corroborates previous conclusions that hitters had less control over their presenting situation than pitchers did (Zizzi et al., 2003). Also, in a previous study conducted with professional baseball players in the Korean Baseball Organization, Han et al., (2014) found that skills such as imagery could provide hitters with a flexible coping method for anxiety and help with attention shifting and performance enhancement. Parallel to the findings of this study, practitioners could help hitters reappraise the somatic anxiety intensity that they perceive into their control and redirect their attention to the task of hitting through imagery could potentially improve their BABIP. Practitioners could emphasize elements that are within a hitter's control, such as choosing certain pitches or locations to swing at when in double play situations. Additionally, imagery was found to be useful to improve self-confidence within baseball players and helped improve their performance in a study conducted by Davis and Sime (2005). With the finding that higher levels of self-confidence help hitters ground into less double plays, practitioners could work on the cognitive reappraisal (De Castella et al., 2013) of their self- 
confidence and help hitters practice brief imagery or mental rehearsals to improve their selfconfidence.

Practitioners could use the findings of this study to target certain mental skills to help pitchers improve their commitment and hitters their sense of control. Hardiness and the subconstructs of challenge, control, commitment seem to lend themselves to mental skills and overlap with similar constructs taught to help address situational anxiety. Mental skills such as mindfulness awareness to help identify things that are within one's control (Chen et al., 2019) could be one way to help improve a hitter's performance. For pitchers, refocusing one's commitment to a pitch by shifting a pitcher's attention from a narrow internal focus to a narrow external focus according to Nideffer and Sagal (2006) model of attentional control when perceiving high intensities of cognitive or somatic anxiety could help pitchers improve performance with runners on-base. These mental skills implemented through sessions that utilize cognitive behavioral interventions to increase hardiness (Thompson \& Morris, 2017) or overall motivational climate (Smith et al., 2007) could be useful interventions to help pitchers or hitters during these specific situations. These findings could also be used by collegiate baseball teams or professional baseball organizations and coaches as moments of emphasis to help remind pitchers to stay committed perhaps during a mound visit with runners on base. Organizations could use this information as areas of emphasis for pitchers or hitters to focus on during player development or recruitment and paired with mental skills consultants, who are more commonly positioned within professional baseball teams, could help develop these skills to help their players and team handle these situations. 


\section{Limitations}

The first limitation to consider when interpreting this study's findings is the shortened data collection period for games played and statistics accrued due to the global COVID-19 pandemic. Less statistics accumulated could be an inaccurate representation of a player's performance due to the small sample size. Often, both hitters and pitchers will go through streaks or slumps throughout the season and might perform better depending on the time of the season. Most games played in this shortened season were against non-conference opponents, who teams might not play yearly and are typically treated as tune-up games for a team's conference schedule. Additionally, the shortened season might also have prevented injured players or those not receiving initial playing time from being represented in the study. Although these statistics might not represent a typical season, ultimately the findings of this study are still contributory to extant research and the field's understanding of hardiness' influence on objective performance, specifically with newer baseball statistics rarely seen in research.

Another limitation could stem from the self-report and voluntary nature of the study's participant recruitment. The participation from teams varied, as some were mandated by their coach to participate and other coaches made it voluntary to participate. Self-selection to participate through this voluntary nature could cause participants who have higher levels of hardiness or less anxious to elect to participate in the study. Also, participants who were mandated to participate or thought that the coach might view their responses may have been less forthright with their answers and responses. In a similar vein, this study relied on participant's abilities to self-report and assess their own personality characteristics and anxiety intensity. Personality is still among the least understood or measurable elements of an individual's disposition and relying on a participant's ability to self-assess their personality can be 
challenging. However, self-report measures might still be the most appropriate when there is a lack of other more accurate assessments (Chan, 2009). Perhaps in future research, a triangulation method of a self-reported measure from the participant and from their coach who is observing them in many of their athletic settings could be more appropriate.

Additionally, personality self-assessments were conducted in the offseason to provide the least burden to the players and teams participating. These offseason trait anxiety and hardiness self-assessments were used to compare and predict future objective performance during the shortened season. Some considerations of the timing of assessments used to predict future situational performance should be acknowledged. Future studies should consider multiple timepoints of personality assessments throughout the season paired with possible qualitative interviews to determine if the moderating effects of hardiness are consistent throughout situational states during a baseball season.

Finally, a few objective performance statistics analyzed may contain subjectivity by the official scorer due to the nature of baseball's rules. Statistics such as wild pitches and grounding into double plays contain certain situations where subjective calls are made by the official scorer. For example, a wild pitch occurs when a pitcher throws a ball that allows a runner to advance to the next base. However, if it is deemed that the catcher is at fault for the advancement of the runner and not the pitcher, then it is considered a pass ball and not a wild pitch. So, on the same play, a result can either be considered a wild pitch or a passed ball but is determined by the NCAA official scorer. Although there is subjectivity in a few of these calls, the majority of the time the scorer has a clear-cut interpretation and subjective calls are rare. However, the element of subjectivity should be acknowledged when considering these statistics. 


\section{Future Research}

A replication of this study under more normal circumstances if and when possible would be an ideal first future direction. Given that this study was only able to collect one-fourth of a typical collegiate baseball season's worth of statistics, a follow-up study that collects a full season's statistics to replicate the findings exhibited in this study would be worthwhile. A replication study would also be useful to corroborate the validity and reliability of the truncated or updated version of the PVS III-R used in this sport-related study. Future research could also include more qualitative assessments to gain a player's reflection of their understanding of their own personality and examine the metacognition or self-awareness of athletes and how they perceive their personality affecting their sport performance. This triangulation could provide a mixed-methods approach to help understand if self-reported data could be relied upon for hardiness or other personality measurements.

Future studies including more qualitative interviews on state-like personality contexts could be increasingly contributory. Since the data of this study tend to suggest that there may be more state-like moderating effects of personality on a pitcher or hitter's situational performance, future studies examining these relationships could be enlightening. These qualitative studies would offer more accurate assessments of constructs within specific settings or domains and may be better able to isolate, for example, what specific situations a hitter's cognitive and somatic anxiety are intensified instead of just grounding into double plays. With questionnaires and interviews that ask athletes to reflect upon specific pressure situations during games, future researchers may be able to better isolate or corroborate situational findings found in this study. Experimental research could also be beneficial to examine how trait anxiety could help or hurt 
performance in controlled settings which has been done in some previously similar studies (Geukes et al., 2017).

Additionally, future research exploring the moderating effect of hardiness on anxiety's intensity or interpretation by an athlete within other divisions of NCAA baseball, professional levels, or other sports and their objective performance metrics could be useful to see if these moderating effects are present in other sports or settings. Future studies within professional baseball could investigate other statistics such as spin rate, league-normed statistics, and technologically-based Hawkeye program statistics that are installed in major league stadiums would be useful to be considered as well. The statistics that were chosen in this study were limited by the feasibility of hand-calculating the statistics given box scores provided by publicly available games. If given access to more complicated statistics that may better represent true metrics of performance, a replication of the methods of this study on the moderation of those statistics would be contributory. Future research could also extend to coaches and officials who also face adversities or feel intense cognitive or somatic anxiety and could moderate their performance through higher levels of hardiness.

Future longitudinal would also be ideal to identify if characteristics like hardiness, which have been understood to develop or become established over time, are more salient during certain developmental periods or after certain challenging or adverse events. If it can be shown that personality characteristics can be built up or developed, interventions for personality characteristics would be beneficial to see if it is possible to establish certain characteristics. Longitudinal following high school athletes as they go through developmental stages would help identify if and when hardiness starts to develop in an athlete's career. This could give researchers insight about when and how to best instill interventions that could help athletes develop 
hardiness or other characteristics and help identify individuals who may or may not have levels of hardiness as they go through transitions in their athletic career. A repeated-measures approach that follows and measures players throughout a season and matches it up to performance throughout the season would also be a beneficial future direction. There are many avenues still left to be explored, understood, and examined within the sport personality research.

\section{Conclusion}

Hardiness has been commonly measured as one construct altogether, but previous studies have proposed the possibility of separating the three sub-components of challenge, control, and commitment and treating those as their own constructs as well (Sheard \& Golby, 2006). Findings in this study were significant for commitment or control but not in total hardiness supporting the suggestion that these sub-constructs of hardiness could be better addressed individually by practitioners during mental skills interventions. Significant findings for the moderating effects of commitment accounted for the majority of variance within situations with runners on base for pitchers while significant moderations accounted for less variance for hitters and control. Overall, this study partially corroborates correlational findings previously found in a similar objective performance study in collegiate baseball and the moderating effect findings support previous interpretations that hitters have less control than pitchers within baseball (Zizzi et al., 2003). Additionally, in the time since that study was published, baseball analysts have added numerous statistics to attempt to isolate and represent more advanced objective performance metrics which were explored in the current study. This study also expands upon previous work that identified hardiness and trait anxiety as important individual difference variables by examining the possible moderating effect of hardiness on the relationship between trait anxiety and objective performance in sport (Hanton et al., 2013). 
Some limitations include the shortened season statistics due to the COVID-19 pandemic, voluntary nature of self-report surveys among members of different teams, data collection timing related to situational interpretations, and possible subjectivity in certain baseball statistics. Finally, future directions include a replication of this study over a full season when and if possible, to corroborate situational findings utilizing mixed methods including qualitative interviews paired with multiple timepoint assessments of personality to closely match states to performance, and possible interventions to identify if improving hardiness can increase objective performance through the implementation of mental skills. 


\section{References}

Allen, M. S., Greenlees, I., \& Jones, M. (2013). Personality in sport: A comprehensive review. International Review of Sport and Exercise Psychology, 6(1), 184-208. doi:10.1080/1750984X.2013.769614

Allen, M. S., \& Laborde, S. (2014). The role of personality in sport and physical activity. Current Directions in Psychological Science, 23(6), 460-465. doi:10.1177/0963721414550705

Allen, M. S., Magee, C. A., Vella, S. A., \& Laborde, S. (2017). Bidirectional associations between personality and physical activity in adulthood. Health Psychology, 36(4), 332336. doi:10.1037/hea0000371

Bartone, P. T., Ursano, R. J., Wright, K. M., \& Ingraham, L. H. (1989). The impact of a military air disaster on the health of assistance workers. Journal of nervous and mental disease, 177(6), 317-328.

Cattell, R. B. (1965). A biometrics invited paper. Factor analysis: an introduction to essentials I. The purpose and underlying models. Biometrics, 21(1), 190-215.

Chang, M.O., \& Torres, A. C. M. (2019). Multidimensional diagnosis of competitive anxiety in youth baseball team. International research journal of management, IT and social sciences, 6(6), 104-110.

Chen, J. H., Tsai, P. H., Lin, Y.C., Chen, C. K., \& Chen, C. Y. (2019). Mindfulness training enhances flow state and mental health among baseball players in Taiwan. Psychology research and behavior management, 12, 15 .

Connor, K. M., \& Davidson, J. R. T. (2003). Development of a new resilience scale: The connordavidson resilience scale (CD-RISC). Depression and anxiety, 18(2), 76-82. 
Costa, P. T., \& McCrae, R. R. (1985). The NEO personality inventory.

Coulter, T. J., Mallett, C. J., \& Singer, J. A. (2018). A three-domain personality analysis of a mentally tough athlete. European Journal of Personality, 32(1), 6-29. doi:10.1002/per.2129

Credé, M., Tynan, M. C., \& Harms, P. D. (2017). Much ado about grit: A meta-analytic synthesis of the grit literature. Journal of Personality and Social Psychology, 113(3), 492-511. doi:10.1037/pspp0000102

Crust, L., \& Clough, P. J. (2005). Relationship between mental toughness and physical endurance. Perceptual and Motor Skills, 100(1), 192-194.

Davis, P. A., \& Sime, W. E. (2005). Toward a psychophysiology of performance: Sport psychology principles dealing with anxiety. International Journal of Stress Management, 12(4), 363.

De Castella, K., Goldin, P., Jazaieri, H., Ziv, M., Dweck, C. S., \& Gross, J. J. (2013). Beliefs about emotion: Links to emotion regulation, well-being, and psychological distress. Basic and Applied Sport Psychology, 35(6), 497-505.

Devin Fahim, H., Farbod, D., Ghasabian, H., Bidel, T., \& Ghahremanlou, F. (2015).

Comparative and correlative study of psychological hardiness and competitiveness among female student athletes in individual and team sports. Sport Science Review, 24(3/4), 201-213. doi:10.1515/ssr-2015-0016

Duckworth, A. L., Peterson, C., Matthews, M. D., \& Kelly, D. R. (2007). Grit: Perseverance and passion for long-term goals. Journal of Personality and Social Psychology, 92(6), 1087 1101. doi:10.1037/0022-3514.92.6.1087

Duckworth, A. L., \& Quinn, P. D. (2009). Development and validation of the short grit scale 
(GRIT-S). Journal of personality assessment, 91(2), 166-174.

Eschleman, K. J., Bowling, N. A., \& Alarcon, G. M. (2010). A meta-analytic examination of hardiness. International Journal of Stress Management, 17(4), 277-307. doi:10.1037/a0020476

Eysenck, H. J., \& Eysenck, S. B. G. (1964). Manual of the eysenck personality inventory: University of London Press.

FanGraphs Baseball | Baseball Statistics and Analysis. (n.d.). Retrieved April 19, 2019, from https://www.fangraphs.com/

Florian, V., Mikulincer, M., \& Taubman, O. (1995). Does hardiness contribute to mental health during a stressful real-life situation? The roles of appraisal and coping. Journal of Personality and Social Psychology, 68(4), 687-695. doi:10.1037/0022-3514.68.4.687

Ford, I. W., Eklund, R. C., \& Gordon, S. (2000). An examination of psychosocial variables moderating the relationship between life stress and injury time-loss among athletes of a high standard. Journal of Sports Sciences, 18(5), 301-312.

Friborg, O., Hjemdal, O., Rosenvinge, J. H., \& Martinussen, M. (2003). A new rating scale for adult resilience: What are the central protective resources behind healthy adjustment? International journal of methods in psychiatric research, 12(2), 65-76.

Galli, N., \& Gonzalez, S. P. (2015). Psychological resilience in sport: A review of the literature and implications for research and practice. International Journal of Sport \& Exercise Psychology, 13(3), 243-257.

George, T. R. (1994). Self-confidence and baseball performance: A causal examination of selfefficacy theory. Journal of sport and exercise psychology, 16(4), 381-399.

Geukes, K., Harvey, J. T., Trezise, A., \& Mesagno, C. (2017). Personality and performance in 
real-world competitions: Testing trait activation of fear of negative evaluation, dispositional reinvestment, and athletic identity in the field. Psychology of Sport and Exercise, 30, 101-109. doi:10.1016/j.psychsport.2017.02.008

Golby, J., \& Sheard, M. (2004). Mental toughness and hardiness at different levels of rugby league. Personality and Individual Differences, 37(5), 933-942. doi:10.1016/j.paid.2003.10.015

Golby, J., Sheard, M., \& Van Wersch, A. (2007). Evaluating the factor structure of the psychological performance inventory. Perceptual and Motor Skills, 105(1), 309-325.

Goss, J. D. (1994). Hardiness and mood disturbances in swimmers while overtraining. Journal of Sport \& Exercise Psychology, 16(2), 135-149.

Gucciardi, D. F. (2017). Mental toughness: Progress and prospects. Current Opinion in Psychology, 16, 17-23. doi:10.1016/j.copsyc.2017.03.010

Gucciardi, D. F., Hanton, S., Gordon, S., Mallett, C. J., \& Temby, P. (2015). The concept of mental toughness: Tests of dimensionality, nomological network, and traitness. Journal of Personality, 83(1), 26-44. doi:10.1111/jopy.12079

Han, D. H., Kim, B. N., Cheong, J. H., Kang, K. D., \& Renshaw, P. F. (2014). Anxiety and attention shifting in professional baseball players. International journal of sports medicine, 35(8), 708 .

Hanton, S., \& Connaughton, D. (2002). Perceived control of anxiety and its relationship with self-confidence and performance: A qualitative explanation. Research Quarterly for Exercise and Sport, 73, 87-97.

Hanton, S., Neil, R., \& Evans, L. (2013). Hardiness and anxiety interpretation: An investigation into coping usage and effectiveness. European Journal of Sport Science, 13(1), 96-104. 
doi:10.1080/17461391.2011.635810

Hayes, A. F. (2012). PROCESS: A versatile computational tool for observed variable mediation, moderation, and conditional process modeling [White paper]. http://www.afhayes.com/ public/process2012.pdf.

Hayes, A. F. (2013). Introduction to mediation, moderation, and conditional process analysis: A regression-based approach. New York, NY: Guilford Press.

Hu, L. T., \& Bentler, P. M. (1999). Cutoff criteria for fit indexes in covariance structure analysis: Conventional criteria versus new alternatives. Structural Equation Modeling: A Multidisciplinary Journal, 6(1), 1-55.

Jameson, P. R. (2012). The effects of a hardiness educational intervention on hardiness and perceived stress of baccalaureate nursing students. (Unpublished doctoral dissertation), School of Nursing, Widener University.

Kline, T. J. (2005). Psychological testing: A practical approach to design and evaluation. Thousand Oaks, CA: Sage Publications, Inc.

Kobasa, S. C. (1979). Stressful life events, personality, and health: An inquiry into hardiness. Journal of Personality and Social Psychology, 37(1), 1-11. doi:10.1037/0022-3514.37.1.

Kobasa, S. C., Maddi, S. R., \& Kahn, S. (1982). Hardiness and health: A prospective study. Journal of Personality and Social Psychology, 42(1), 168-177. doi:10.1037/00223514.42.1.168

Kobasa, S. C., Maddi, S. R., \& Puccetti, M. C. (1982). Personality and exercise as buffers in the stress-illness relationship. Journal of Behavioral Medicine, 5(4), 391-404. doi:10.1007/BF00845369

Laborde, S., Allen, M. S., Katschak, K., Mattonet, K., \& Lachner, N. (2019). Trait personality in 
sport and exercise psychology: A mapping review and research agenda. International Journal of Sport and Exercise Psychology, 1-16. doi:10.1080/1612197X.2019.1570536

Lagos, L., Vaschillo, E., Vaschillo, B., Lehrer, P., Bates, M., \& Pandina, R. (2008). Heart rate variability biofeedback as a strategy for dealing with competitive anxiety: A case study. Biofeedback, 36(3), 109.

Li, C. H. (2014). The performance of MLR, USLMV, and WLSMV estimation in structural regression models with ordinal variables (Doctoral dissertation, Michigan State University).

Luthar, S. S., Cicchetti, D., \& Becker, B. (2000). The construct of resilience: A critical evaluation and guidelines for future work. Child development, 71(3), 543-562.

MacCann, C., \& Roberts, R. D. (2010). Do time management, grit, and self-control relate to academic achievement independently of conscientiousness?

Maddi, S. R. (1997). Personal views survey II: A measure of dispositional hardiness.

Maddi, S. R. (2002). The story of hardiness: Twenty years of theorizing, research, and practice. Consulting Psychology Journal: Practice and Research, 54(3), 173-185. doi:10.1037/1061-4087.54.3.173

Maddi, S. R. (2006). Hardiness: The courage to grow from stresses. The Journal of Positive Psychology, 1(3), 160-168. doi:10.1080/17439760600619609

Maddi, S. R., Harvey, R. H., Khoshaba, D. M., Lu, J. L., Persico, M., \& Brow, M. (2006). The personality construct of hardiness, III: Relationships with repression, innovativeness, authoritarianism, and performance. Journal of Personality, 74(2), 575-598. doi:10.1111/j.1467-6494.2006.00385.x

Maddi, S. R., \& Khoshaba, D. M. (2001). Personal views survey: Hardiness Institute. 
Maddi, S. R., Khoshaba, D. M., Persico, M., Lu, J., Harvey, R., \& Bleecker, F. (2002). The personality construct of hardiness: II. Relationships with comprehensive tests of personality and psychopathology. Journal of Research in Personality, 36(1), 72-85. doi:10.1006/jrpe.2001.2337

Maddi, S. R., Matthews, M. D., Kelly, D. R., Villarreal, B., \& White, M. (2012). The role of hardiness and grit in predicting performance and retention of USMA cadets. Military Psychology, 24(1), 19-28. doi:10.1080/08995605.2012.639672

Martin, J. J., Byrd, B., Watts, M. L., \& Dent, M. (2015). Gritty, hardy, and resilient: Predictors of sport engagement and life satisfaction in wheelchair basketball players. Journal of Clinical Sport Psychology, 9(4), 345-359. doi:10.1123/jcsp.2015-0015

McAdams, D. P., \& Olson, B. D. (2010). Personality development: Continuity and change over the life course. Annual Review of Psychology, 61, 517-542. doi:10.1146/annurev.psych.093008.100507

McCrae, R. R., \& Costa, P. T., Jr. (2008). Empirical and theoretical status of the five-factor model of personality traits. In G. J. Boyle, G. Matthews, \& D. H. Saklofske (Eds.), The SAGE handbook of personality theory and assessment, Vol 1: Personality theories and models. (pp. 273-294). Thousand Oaks, CA: Sage Publications, Inc.

Middleton, S. C., Marsh, H. W., Martin, A. J., Richards, G. E., Savis, J., Perry Jr, C., \& Brown, R. (2004). The psychological performance inventory: Is the mental toughness test tough enough? International Journal of Sport Psychology.

Morris, T. (2011). Personality and individual differences. In T. Morris \& P. Terry (Eds.), The new sport and exercise psychology companion (pp. 11-36). Morgantown, WV: Fitness Information Technology. 
Muthén, L. K., \& Muthén, B. O. (2010). Mplus User's Guide: Statistical Analysis with Latent Variables: User's Guide. https://www.statmodel.com/html_ug.shtml.

Muthén, B. O., \& Muthén, L. K. (2017). Software Mplus Version 8.

Nideffer, R. \& Sagal, M. (2006). Concentration and attention control training. In J. M. Williams (Ed.), Applied sport psychology: Personal growth to peak performance (pp. 382-403). New York, NY: McGraw-Hill.

Nowack, K. M. (1990). Initial development of an inventory to assess stress and health risk. American Journal of Health Promotion, 4(3), 173-180.

Parfitt, C. G., Jones, J. G., \& Hardy, L. (1990). Multidimensional anxiety and performance. Stress and performance in sport, 43-80.

Piedmont, R. L., Hill, D. C., \& Blanco, S. (1999). Predicting athletic performance using the fivefactor model of personality. Personality and Individual Differences, 27(4), 769-777.

Price, J. P. B. (2019). Testing construct redundancy: Resilience, grit, hardiness, and mental toughness. (Other Degree thesis), Saint Mary’s University, http://library2.smu.ca/handle/01/29003\#.XWgeMihKiUk

Reivich, K. J., Seligman, M. E., \& McBride, S. (2011). Master resilience training in the US Army. American Psychologist, 66(1), 25.

Roberts, R., \& Woodman, T. (2017). Personality and performance: Moving beyond the big 5. Current Opinion in Psychology, 16, 104-108. doi:10.1016/j.copsyc.2017.03.033

Salim, J., Wadey, R., \& Diss, C. (2016). Examining Hardiness, Coping and Stress-Related Growth Following Sport Injury. Journal of Applied Sport Psychology, 28(2), 154-169. doi:10.1080/10413200.2015.1086448

Sarkar, M., \& Fletcher, D. (2014). Psychological resilience in sport performers: A review of 
stressors and protective factors. Journal of Sports Sciences, 32(15), 1419-1434.

Secades, X. G., Molinero, O., Salguero, A., Barquín, R. R., de la Vega, R., \& Márquez, S. (2016). Relationship between resilience and coping strategies in competitive sport. Perceptual and Motor Skills, 122(1), 336-349. doi:10.1177/0031512516631056

Sheard, M., \& Golby, J. (2006). Effect of a psychological skills training program on swimming performance and positive psychological development. International Journal of Sport and Exercise Psychology, 4(2), 149-169. doi:10.1080/1612197X.2006.9671790

Sheard, M., \& Golby, J. (2010). Personality hardiness differentiates elite-level sport performers. International Journal of Sport \& Exercise Psychology, 8(2), 160-169. doi:10.1080/1612197X.2010.9671940

Slowinski, S. (2010). Sabermetrics Library. Fangraphs. https://library.fangraphs.com

Smith, B. W., Dalen, J., Wiggins, K., Tooley, E., Christopher, P., \& Bernard, J. (2008). The brief resilience scale: Assessing the ability to bounce back. International journal of behavioral medicine, 15(3), 194-200.

Smith, R. E., Smoll, F. L., \& Cumming, S. P. (2007). Effects of a motivational climate intervention for coaches on young athletes' sport performance anxiety. Journal of sport and exercise psychology, 29(1), 39-59.

Spielberger, C. D. (1985). Assessment of state and trait anxiety: Conceptual and methodological issues. Southern Psychologist.

Stoffel, J. M., \& Cain, J. (2018). Review of grit and resilience literature within health professions education. American Journal of Pharmaceutical Education, 82(2), 124-134. doi:10.5688/ajpe6150

Strack, B. W. (2003). Effect of heart rate variability (hrv) biofeedback on batting performance in 
baseball. Dissertation Abstracts International: Section B: The Sciences and Engineering, 64(3-B), 1540.

Thomas, S., Reeves, C., Agombar, J., \& Greenlees, I. (2013). Personality hardiness at different levels of competitive motorcycling. Perceptual and Motor Skills, 116(1), 315-321. doi:10.2466/30.06.PMS.116.1.315-321

Thompson, C. (2017). Improving hardiness in elite rugby players. (Other Degree thesis), Victoria University, http://vuir.vu.edu.au/34210/

Vealey, R. S., \& Perritt, N. C. (2015). Hardiness and optimism as predictors of the frequency of flow in collegiate athletes. Journal of Sport Behavior, 38(3), 321-338.

Wadey, R., Evans, L., Hanton, S., \& Neil, R. (2012a). An examination of hardiness throughout the sport injury process. British Journal of Health Psychology, 17(1), 103-128. doi:10.1111/j.2044-8287.2011.02025.x

Wadey, R., Evans, L., Hanton, S., \& Neil, R. (2012b). An examination of hardiness throughout the sport-injury process: A qualitative follow-up study. British Journal of Health Psychology, 17(4), 872-893. doi:10.1111/j.2044-8287.2012.02084.x

Wadey, R., \& Hanton, S. (2008). Basic psychological skill usage and competitive anxiety responses: Perceived underlying mechanisms. Research Quarterly for Exercise and Sport, 79, 363-373.

Wagnild, G., \& Young, H. (1993). Development and psychometric. Journal of nursing measurement, 1(2), 165-17847.

Windle, G., Bennett, K. M., \& Noyes, J. (2011). A methodological review of resilience measurement scales. Health \& Quality of Life Outcomes, 9(1), 8-25. doi:10.1186/14777525-9-8 
Zizzi, S. J., Deaner, H. R., \& Hirschhorn, D. K. (2003). The relationship between emotional intelligence and performance among college baseball players. Journal of Applied Sport Psychology, 15(3), 262-269. doi:10.1080/10413200305390 


\section{Tables}

Table 1

Overall Descriptive Statistics for Participants

\begin{tabular}{|c|c|c|c|c|c|c|}
\hline & \multicolumn{2}{|c|}{$\begin{array}{c}\text { All Participants } \\
(n=389)\end{array}$} & \multicolumn{2}{|c|}{$\begin{array}{l}\text { Pitchers } \\
(n=80)\end{array}$} & \multicolumn{2}{|c|}{$\begin{array}{l}\text { Hitters } \\
(n=94)\end{array}$} \\
\hline & $M$ & $S D$ & $M$ & SD & $\mathbf{M}$ & SD \\
\hline $\operatorname{Age}^{a}$ & 19.85 & 1.24 & 20.01 & 1.27 & 20.20 & 1.20 \\
\hline Athletic Class ${ }^{b}$ & 2.25 & 1.12 & 2.42 & 1.11 & 2.66 & 1.08 \\
\hline Total Hardiness & 17.13 & 3.91 & 17.09 & 3.57 & 17.03 & 3.88 \\
\hline Challenge & 4.90 & 1.66 & 4.86 & 1.48 & 5.01 & 1.75 \\
\hline Control & 5.90 & 1.59 & 5.74 & 1.60 & 5.72 & 1.71 \\
\hline Commitment & 6.33 & 1.68 & 6.49 & 1.51 & 6.30 & 1.64 \\
\hline \multicolumn{7}{|c|}{ Trait Anxiety Intensity } \\
\hline Cognitive Anxiety & 16.81 & 6.08 & 15.52 & 6.34 & 16.73 & 5.28 \\
\hline Somatic Anxiety & 15.25 & 5.46 & 14.80 & 6.08 & 15.02 & 4.41 \\
\hline Self-Confidence & 26.45 & 7.65 & 25.62 & 9.13 & 27.93 & 6.69 \\
\hline \multicolumn{7}{|c|}{ Trait Anxiety Interpretation ${ }^{\mathrm{c}}$} \\
\hline Cognitive Anxiety & 0.13 & 9.59 & -0.12 & 9.38 & -1.49 & 9.43 \\
\hline Somatic Anxiety & -0.97 & 7.96 & -1.40 & 7.17 & -1.96 & 8.47 \\
\hline Self-Confidence & 12.29 & 9.50 & 13.11 & 8.53 & 13.10 & 9.99 \\
\hline
\end{tabular}

Note. ${ }^{a}$ Age in years.

${ }^{\mathrm{b}}$ Athletic Class is coded as $1=$ freshman, $1.5=$ redshirt freshman, $2=$ sophomore, $2.5=$ redshirt sophomore, $3=$ junior, $3.5=$ redshirt freshman, $4=$ senior, $4.5=$ redshirt freshman, $5=$ fifth-year student, $6=$ graduate student.

${ }^{\mathrm{c}}$ CTAI-2 Interpretation individual item Likert responses ranged from -3 to 3 
Table 2

Correlations Among Objective Performance Statistics and Personality for Pitchers

\begin{tabular}{|c|c|c|c|c|c|c|c|c|c|c|}
\hline & 1 & 2 & 3 & 4 & 5 & 6 & 7 & 8 & 9 & 10 \\
\hline 1. Total Hardiness & - & & & & & & & & & \\
\hline 2. Challenge & $.71 * *$ & - & & & & & & & & \\
\hline 3. Control & $.83 * *$ & $.36^{* *}$ & - & & & & & & & \\
\hline 4. Commitment & $.80 * *$ & $.31 * *$ & $.55^{* *}$ & - & & & & & & \\
\hline \multicolumn{11}{|l|}{$\underline{\text { Trait Anxiety Intensity }}$} \\
\hline 5. Cognitive Anxiety Intensity & .13 & .01 & .11 & .18 & - & & & & & \\
\hline 6. Somatic Anxiety Intensity & .16 & .03 & .19 & .13 & $.75 * *$ & - & & & & \\
\hline 7. Self-Confidence Intensity & $.26^{*}$ & .08 & $.23 *$ & $.31 * *$ & $.64 * *$ & $.62 * *$ & - & & & \\
\hline \multicolumn{11}{|l|}{ Trait Anxiety Interpretation } \\
\hline 8. Cognitive Anxiety Interpretation & .06 & .01 & .06 & .07 & -.04 & -.09 & -.17 & - & & \\
\hline 9. Somatic Anxiety Interpretation & .15 & .17 & .16 & .01 & -.16 & -.12 & -.21 & $.82 * *$ & - & \\
\hline 10. Self-Confidence Interpretation & $.34 * *$ & .16 & $.34 * *$ & $.30 * *$ & .10 & .21 & $.41 * *$ & .07 & .03 & - \\
\hline \multicolumn{11}{|l|}{ Objective Performance Statistics } \\
\hline 11. Walks \& Hits Per Innings Pitched & .05 & -.02 & .03 & .11 & .17 & .12 & .09 & -.03 & -.07 & -.15 \\
\hline 12. Hits & -.05 & -.13 & .02 & -.02 & .01 & .10 & .12 & -.18 & -.18 & .05 \\
\hline 13. Earned Runs & .03 & -.07 & .05 & .08 & -.03 & .05 & .08 & -.12 & -.13 & .02 \\
\hline 14. Walks & $.26^{*}$ & .09 & $.22 *$ & $.30 * *$ & -.05 & .04 & .15 & -.18 & -.14 & .14 \\
\hline 15. Strikeouts & .08 & -.05 & .16 & .07 & .02 & .10 & .11 & $-.23 *$ & -.21 & $.24 *$ \\
\hline 16. Wild Pitches & .10 & -.11 & .11 & $.23 *$ & .16 & .11 & .14 & -.11 & -.14 & .02 \\
\hline 17. Fielding Independent Pitching & .07 & -.02 & .04 & .14 & .01 & -.06 & -.01 & .03 & .00 & -.07 \\
\hline 18. Left on-Base Percentage & -.03 & .04 & -.02 & -.09 & .06 & .02 & .05 & .01 & .05 & .17 \\
\hline 19. Batting Average on Balls in Play & -.05 & -.10 & .00 & -.02 & $.25^{*}$ & .20 & .13 & -.01 & -.07 & -.13 \\
\hline
\end{tabular}

Note. Values are Pearson correlation coefficients among variables. $N=80$. Two-tailed tests were conducted. $* p<.05 * * p<.01$ 
Table 3

Correlations Among Objective Performance Statistics and Personality for Hitters

\begin{tabular}{|c|c|c|c|c|c|c|c|c|c|c|}
\hline & 1 & 2 & 3 & 4 & 5 & 6 & 7 & 8 & 9 & 10 \\
\hline 1. Total Hardiness & - & & & & & & & & & \\
\hline 2. Challenge & $.72 * *$ & - & & & & & & & & \\
\hline 3. Control & $.78 * *$ & $.29 * *$ & - & & & & & & & \\
\hline 4. Commitment & $.79 * *$ & $.34 * *$ & $.50 * *$ & - & & & & & & \\
\hline \multicolumn{11}{|l|}{ Trait Anxiety Intensity } \\
\hline 5. Cognitive Anxiety Intensity & -.20 & -.10 & $-.22 *$ & -.14 & - & & & & & \\
\hline 6. Somatic Anxiety Intensity & $-.21 *$ & -.13 & -.17 & -.17 & $.71 * *$ & - & & & & \\
\hline 7. Self-Confidence Intensity & $.33 * *$ & .09 & $.32 * *$ & $.34 * *$ & .13 & .03 & - & & & \\
\hline \multicolumn{11}{|l|}{ Trait Anxiety Interpretation } \\
\hline 8. Cognitive Anxiety Interpretation & -.03 & .06 & .00 & -.14 & .13 & -.03 & -.01 & - & & \\
\hline 9. Somatic Anxiety Interpretation & -.11 & -.06 & -.01 & -.18 & .10 & .04 & -.14 & $.83 * *$ & - & \\
\hline 10. Self-Confidence Interpretation & $.32 * *$ & .17 & .18 & $.39 * *$ & .08 & -.04 & $.40 * *$ & -.17 & $-.25 *$ & - \\
\hline \multicolumn{11}{|l|}{ Objective Performance Statistics } \\
\hline 11. On-Base Percentage Plus Slugging & -.01 & -.07 & .01 & .03 & -.03 & -.08 & -.08 & .03 & .00 & -.10 \\
\hline 12. Hits & .08 & -.03 & .12 & .11 & -.16 & -.14 & -.03 & -.04 & -.05 & -.10 \\
\hline 13. Doubles & .04 & -.12 & .09 & .14 & .03 & -.06 & .08 & -.07 & -.04 & -.07 \\
\hline 14. Walks & -.05 & -.16 & -.03 & .08 & -.06 & -.12 & -.04 & .07 & .05 & -.07 \\
\hline 15. Strikeouts & .06 & -.02 & .05 & .11 & .01 & -.03 & .15 & -.12 & -.14 & .16 \\
\hline 16. Grounded into Double Plays & -.09 & -.12 & -.08 & .00 & -.06 & .03 & $-.22 *$ & .06 & .05 & -.20 \\
\hline 17. Weighted On-Base Average & -.02 & -.08 & .00 & .04 & -.04 & -.08 & -.09 & .03 & -.01 & -.09 \\
\hline 18. Batting Average on Balls in Play & .09 & -.02 & .10 & .12 & -.17 & -.17 & -.01 & -.10 & -.15 & .05 \\
\hline
\end{tabular}

Note. Values are Pearson correlation coefficients among variables. $N=94$. Two-tailed tests were conducted. $* p<.05 * * p<.01$ 
Table 4

Moderation Effects of Commitment on Relationship between Competitive Trait Anxiety Intensity and Objective Performance for Pitchers

Commitment as Moderator (W)

$\beta \quad S E \quad t \quad p$

p $95 \% \mathrm{CI}$

$R^{2} \quad \Delta R^{2} \quad \Delta R^{2} \%$

Cognitive Anxiety Intensity (X)

(WP) Wild Pitches (Y)

(FIP) Fielding Independent Pitching (Y)

$\begin{array}{lllllllll}0.046 & 0.013 & 3.533 & \mathbf{0 . 0 0 1} & 0.020 & 0.072 & 0.236 & 0.127 & 53.8 \%\end{array}$

(LOB\%) Left on-base Percentage (Y)

$\begin{array}{lllll}0.007 & 0.016 & 0.450 & 0.654 & -0.025\end{array}$

0.040

0.119

0.002

$1.7 \%$

Somatic Anxiety Intensity (X)

(WP) Wild Pitches (Y)

$-0.004 \quad 0.001$

$-2.949$

$\mathbf{0 . 0 0 4}-0.006$

$-0.001$

0.116

0.103

$88.8 \%$

(FIP) Fielding Independent Pitching (Y)

(LOB\%) Left on-base Percentage (Y)

$\begin{array}{ccccccccc}0.043 & 0.013 & 3.181 & \mathbf{0 . 0 0 2} & 0.016 & 0.070 & 0.200 & 0.108 & 54 \% \\ 0.005 & 0.016 & 0.331 & 0.742 & -0.027 & 0.038 & 0.121 & 0.001 & 0.8 \% \\ -0.003 & 0.001 & -2.716 & \mathbf{0 . 0 0 8} & -0.006 & -0.001 & 0.098 & 0.089 & 90.8 \%\end{array}$

Self-Confidence Intensity $(\mathrm{X})$

(WP) Wild Pitches (Y)

$\begin{array}{ccccccccc}0.028 & 0.009 & 2.940 & \mathbf{0 . 0 0 4} & 0.009 & 0.047 & 0.184 & 0.094 & 51.1 \% \\ -0.004 & 0.011 & -0.331 & 0.742 & -0.027 & 0.019 & 0.116 & 0.001 & 0.9 \% \\ -0.002 & 0.001 & -2.095 & \mathbf{0 . 0 4 0} & -0.004 & 0.000 & 0.069 & 0.055 & 79.7 \%\end{array}$

(FIP) Fielding Independent Pitching (Y)

(LOB\%) Left on-base Percentage (Y)

Note. Bolded $\mathrm{p}$ values were significant $p<.05 . \Delta R^{2} \%$ was calculated by dividing $\Delta R^{2}$ by $\Delta R$. 
Table 5

Significant Moderation Conditional Effects of Commitment for Pitchers using Johnson-Neyman Probing Technique

\begin{tabular}{|c|c|c|c|c|c|c|c|c|}
\hline Commitment as Moderator (W) & Conditional Effect Percentile & Sig. Moderator Value & Effect & $S E$ & $t$ & $p$ & \multicolumn{2}{|c|}{$95 \% \mathrm{CI}$} \\
\hline \multicolumn{9}{|l|}{$\underline{\text { Cognitive Anxiety Intensity (X) }}$} \\
\hline (WP) Wild Pitches (Y) & Above $53.75 \%$ & 6.371 & 0.051 & 0.026 & 1.992 & $\mathbf{0 . 0 5 0}$ & 0.000 & 0.102 \\
\hline (WP) Wild Pitches (Y) & Below $1.25 \%$ & 3.399 & -0.086 & 0.043 & -1.992 & $\mathbf{0 . 0 5 0}$ & -0.173 & 0.000 \\
\hline$(\mathrm{LOB} \%)$ Left on-base Percentage (Y) & Above $88.75 \%$ & 8.782 & -0.008 & 0.004 & -1.992 & $\mathbf{0 . 0 5 0}$ & -0.020 & 0.000 \\
\hline (LOB\%) Left on-base Percentage (Y) & Below $26.25 \%$ & 5.062 & 0.005 & 0.003 & 1.992 & $\mathbf{0 . 0 5 0}$ & 0.000 & 0.011 \\
\hline \multicolumn{9}{|l|}{$\underline{\text { Somatic Anxiety Intensity (X) }}$} \\
\hline (WP) Wild Pitches (Y) & Above $72.5 \%$ & 7.046 & 0.058 & 0.029 & 1.992 & $\mathbf{0 . 0 5 0}$ & 0.000 & 0.116 \\
\hline (WP) Wild Pitches (Y) & Below $1.25 \%$ & 3.734 & -0.084 & 0.042 & -1.992 & $\mathbf{0 . 0 5 0}$ & -0.168 & 0.000 \\
\hline (LOB\%) Left on-base Percentage (Y) & Above $88.75 \%$ & 8.856 & -0.008 & 0.004 & -1.992 & $\mathbf{0 . 0 5 0}$ & -0.020 & 0.000 \\
\hline (LOB\%) Left on-base Percentage (Y) & Below $7.5 \%$ & 4.535 & 0.006 & 0.003 & 1.992 & $\mathbf{0 . 0 5 0}$ & 0.000 & 0.013 \\
\hline \multicolumn{9}{|l|}{$\underline{\text { Self-Confidence Intensity }(\mathrm{X})}$} \\
\hline (WP) Wild Pitches (Y) & Above $72.5 \%$ & 7.132 & 0.043 & 0.021 & 1.992 & $\mathbf{0 . 0 5 0}$ & 0.000 & 0.086 \\
\hline (WP) Wild Pitches (Y) & Below $1.25 \%$ & 3.378 & -0.062 & 0.031 & -1.992 & 0.050 & -0.124 & 0.000 \\
\hline (LOB\%) Left on-base Percentage (Y) & Below $7.5 \%$ & 4.007 & 0.005 & 0.002 & 1.992 & $\mathbf{0 . 0 5 0}$ & 0.000 & 0.010 \\
\hline
\end{tabular}

Note. Two-tailed Conditional effect percentile and moderator values were indicators of beginning of ranges of significance for $p<.05$. 
Table 6

Moderation Effects of Control on Relationship between Competitive Trait Anxiety Intensity and Objective Performance for Hitters

Control as Moderator (W)

$\beta$

SE

$\begin{array}{ccccccccc}-0.004 & 0.011 & -0.363 & 0.717 & -0.026 & 0.018 & 0.077 & 0.001 & 1.3 \% \\ 0.000 & 0.001 & 0.241 & 0.801 & -0.002 & 0.003 & 0.038 & 0.001 & 2.6 \% \\ 0.001 & 0.001 & 1.031 & 0.305 & -0.001 & 0.004 & 0.053 & 0.011 & 20.8 \%\end{array}$

Cognitive Anxiety Intensity $(\mathrm{X})$

(GDP Grounded into Double Play (Y)

(wOBA) Weighted On-Base Average (Y)

(BABIP) Batting Average on Balls In Play (Y)

Somatic Anxiety Intensity (X)

(GDP Grounded into Double Play (Y)

(wOBA) Weighted On-Base Average (Y)

(BABIP) Batting Average on Balls In Play (Y)

$\underline{\text { Self-Confidence Intensity (X) }}$

(GDP Grounded into Double Play (Y) (wOBA) Weighted On-Base Average (Y)

(BABIP) Batting Average on Balls In Play (Y)

Note. Bolded $\mathrm{p}$ values were significant $p<.05 . \Delta R^{2}$

$95 \% \mathrm{CI}$

$R^{2}$

$\Delta R^{2} \quad \Delta R^{2} \%$

$\begin{array}{lllllllll}-0.015 & 0.014 & -1.071 & 0.287 & -0.043 & 0.013 & 0.088 & 0.012 & 13.6 \% \\ 0.002 & 0.001 & 1.313 & 0.193 & -0.001 & 0.005 & 0.058 & 0.018 & 31.0 \% \\ 0.003 & 0.001 & 2.152 & \mathbf{0 . 0 3 4} & 0.000 & 0.006 & 0.090 & 0.047 & 52.2 \%\end{array}$

\begin{tabular}{lllllllll}
-0.014 & 0.007 & -2.156 & $\mathbf{0 . 0 3 4}$ & -0.027 & -0.001 & 0.163 & 0.044 & $27.0 \%$ \\
0.001 & 0.001 & 1.655 & 0.102 & 0.000 & 0.003 & 0.076 & 0.028 & $36.8 \%$ \\
0.001 & 0.001 & 0.962 & 0.339 & -0.001 & 0.002 & 0.036 & 0.010 & $27.8 \%$ \\
\hline
\end{tabular}

$\%$ was calculated by dividing $\Delta R^{2}$ by $\Delta R$. 
Table 7

Significant Moderation Conditional Effects of Control for Hitters using Johnson-Neyman Probing Technique

\begin{tabular}{|c|c|c|c|c|c|c|c|c|}
\hline Control as Moderator (W) & $\begin{array}{c}\text { Conditional Effect } \\
\text { Percentile }\end{array}$ & $\begin{array}{l}\text { Sig. Moderator } \\
\text { Value }\end{array}$ & Effect & $S E$ & $t$ & $p$ & \multicolumn{2}{|c|}{$95 \% \mathrm{CI}$} \\
\hline \multicolumn{9}{|l|}{$\underline{\text { Somatic Anxiety Intensity }(\mathrm{X})}$} \\
\hline $\begin{array}{l}\text { (BABIP) Batting Average on Balls In Play } \\
\text { (Y) }\end{array}$ & Below $43.62 \%$ & 5.502 & -0.004 & 0.002 & -1.987 & 0.050 & -0.009 & 0.000 \\
\hline \multicolumn{9}{|l|}{ Self-Confidence Intensity $(X)$} \\
\hline (GDP Grounded into Double Play (Y) & Above $43.62 \%$ & 5.927 & -0.025 & 0.013 & -1.987 & 0.050 & -0.050 & 0.000 \\
\hline
\end{tabular}

Note. Conditional effect percentile and moderator values were indicators of beginning of ranges of significance for $p<.05$. 
Table 8

Summary of CFA Results Depicting Hardiness Sub-Constructs

\begin{tabular}{|c|c|c|}
\hline PVS III-R Hardiness & Standardized Loadings/Estimate & SE \\
\hline \multicolumn{3}{|l|}{$\underline{\text { Control }}$} \\
\hline Item 1. By working hard, you can always achieve your goal. & 0.568 & 0.051 \\
\hline Item 6. When I make plans, I'm certain I can make them work. & 0.514 & 0.048 \\
\hline Item 9. Most of the time, people listen carefully to what I have to say. & 0.404 & 0.050 \\
\hline Item 2. I don't like to make changes in my everyday schedule. & -0.179 & 0.049 \\
\hline Item 5. Most of what happens in life is just meant to be. & -0.191 & 0.049 \\
\hline Item 13 . It bothers me when my daily routine gets interrupted. & -0.205 & 0.052 \\
\hline \multicolumn{3}{|l|}{$\underline{\text { Commitment }}$} \\
\hline Item 3. I really look forward to my work. & 0.474 & 0.044 \\
\hline Item 11 . Trying your best at what you do usually pays off in the end. & 0.543 & 0.043 \\
\hline Item 14. I often wake up eager to take up life where it left off. & 0.447 & 0.046 \\
\hline Item 7. No matter how hard I try, my efforts usually accomplish little. & 0.348 & 0.053 \\
\hline Item 15. Lots of times, I really don't know my own mind. & 0.385 & 0.052 \\
\hline Item 18. It's hard to imagine anyone getting excited about working. & 0.404 & 0.051 \\
\hline \multicolumn{3}{|l|}{ Challenge } \\
\hline Item 4. I am not equipped to handle the unexpected problems of life. & 0.387 & 0.054 \\
\hline Item 10. Thinking of yourself as a free person just leads to frustration. & 0.746 & 0.049 \\
\hline Item 12. My mistakes are usually very difficult to correct. & 0.535 & 0.052 \\
\hline Item 8 . I like a lot of variety in my work. & -0.120 & 0.051 \\
\hline Item 16. Changes in routine provoke me to learn. & -0.203 & 0.049 \\
\hline Item 17. Most days, life is really interesting and exciting for me. & 0.062 & 0.053 \\
\hline
\end{tabular}

Note. Standardized loadings are presented. $S E=$ standard error. Maximum likelihood estimation with robust standard errors and a mean-adjusted chi-square test statistic was employed (Muthén \& Muthén, 2010). 
Table 9

Summary of CFA Results Depicting revised PVS III-R items after initial CFA results

\begin{tabular}{lc}
\hline Revised PVS III-R Hardiness & Standardized Loadings/Estimate \\
\hline Control & SE \\
Item 1. By working hard, you can always achieve your goal. & 0.502 \\
Item 6. When I make plans, I'm certain I can make them work. & 0.544 \\
Item 9. Most of the time, people listen carefully to what I have to say. & 0.451 \\
Commitment & 0.056 \\
Item 3. I really look forward to my work. & 0.055 \\
Item 11. Trying your best at what you do usually pays off in the end. & 0.0575 \\
Item 14. I often wake up eager to take up life where it left off. & 0.048 \\
Challenge & 0.049 \\
Item 8. I like a lot of variety in my work. & 0.586 \\
Item 16. Changes in routine provoke me to learn. & 0.060 \\
Item 17. Most days, life is really interesting and exciting for me. & 0.059 \\
\hline
\end{tabular}

Note. Standardized loadings are presented. $S E=$ standard error. Maximum likelihood estimation with robust standard errors and a mean-adjusted chi-square test statistic was employed (Muthén \& Muthén, 2010). 


\section{Figures}

Figure 1

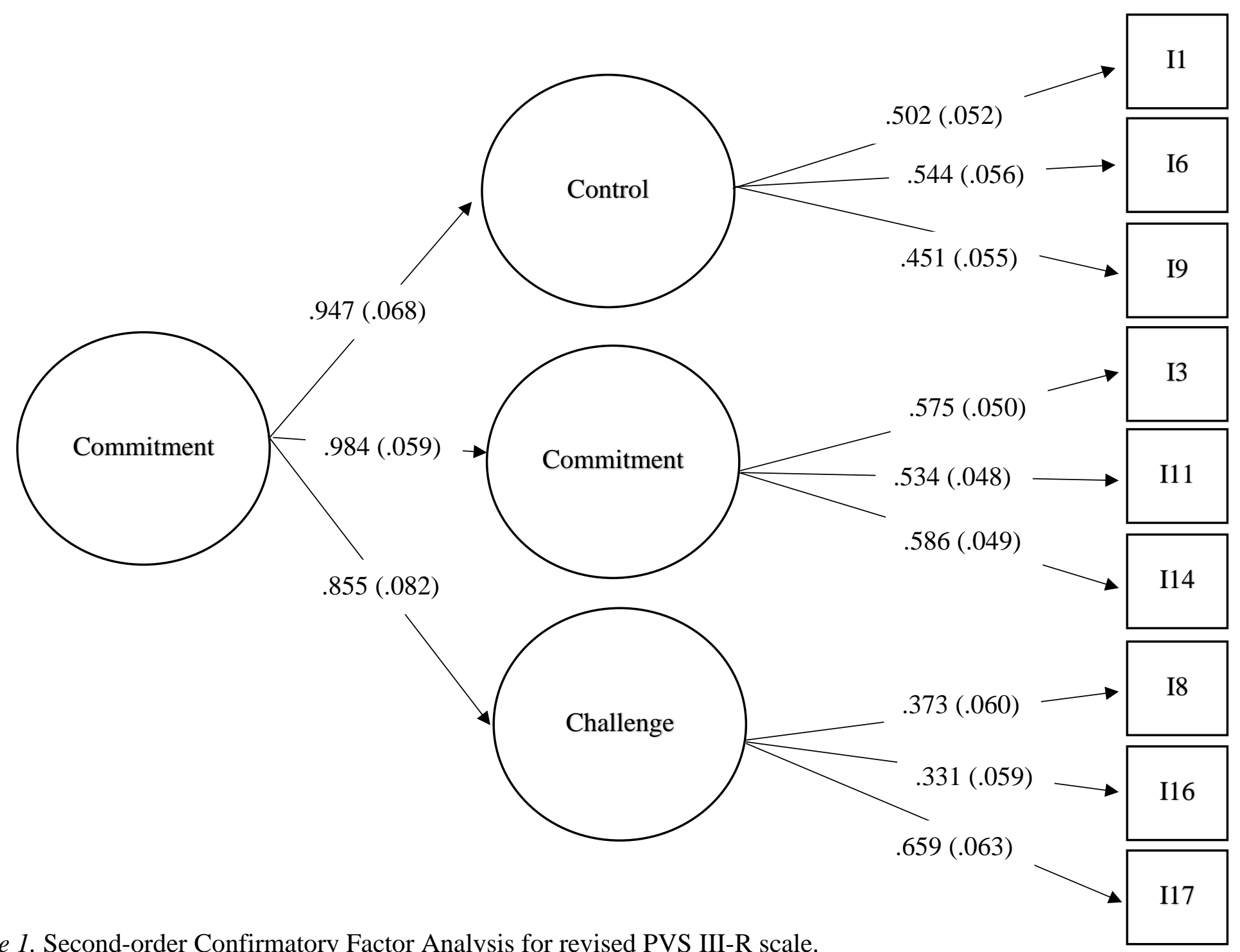

Figure 1. Second-order Confirmatory Factor Analysis for revised PVS III-R scale. 
Figure 2 Sig. Moderation Visualization for Pitchers
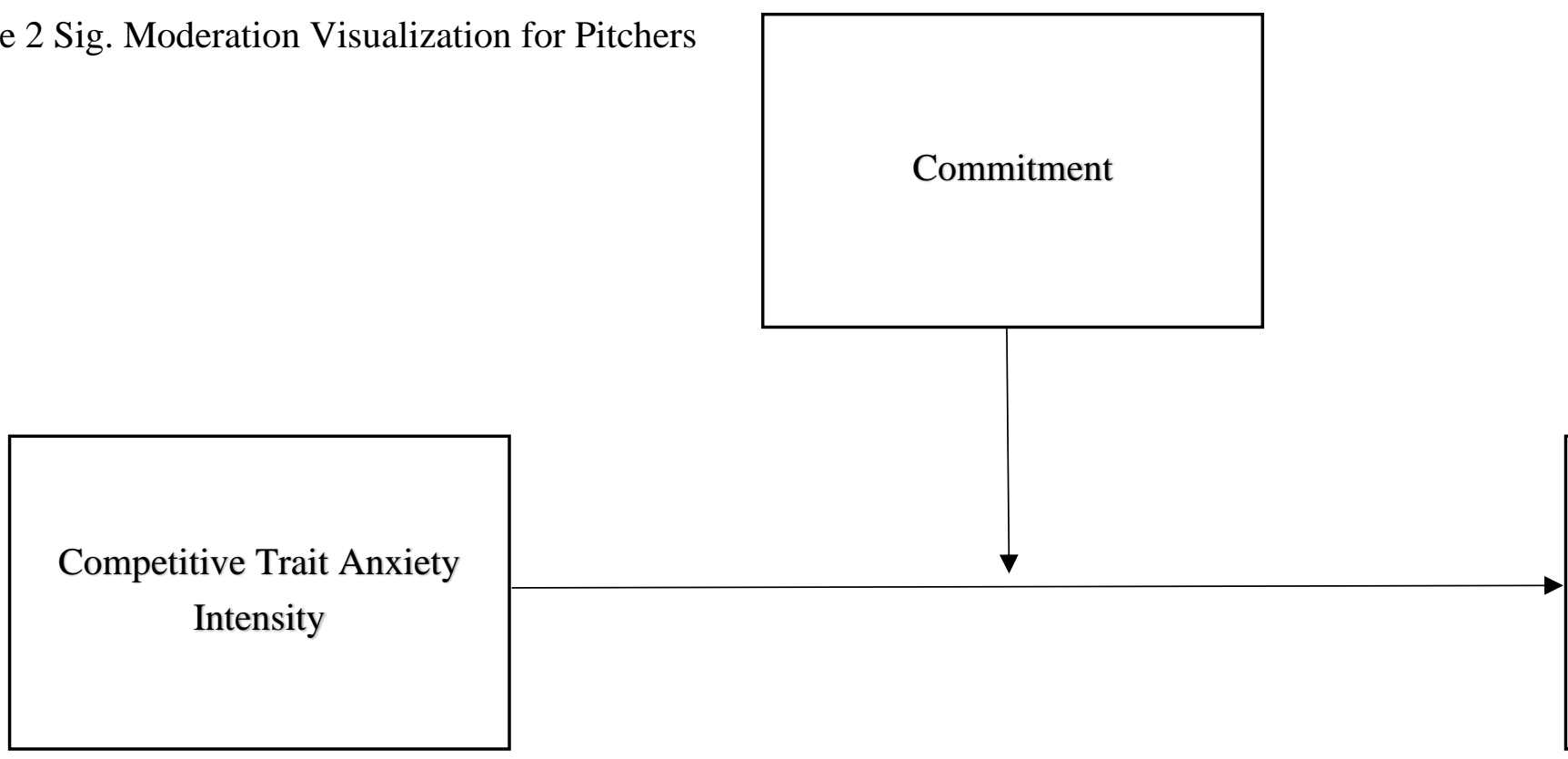

Pitcher's Objective

Performance Statistics

Figure 3 Sig. Moderation Visualization for Hitters
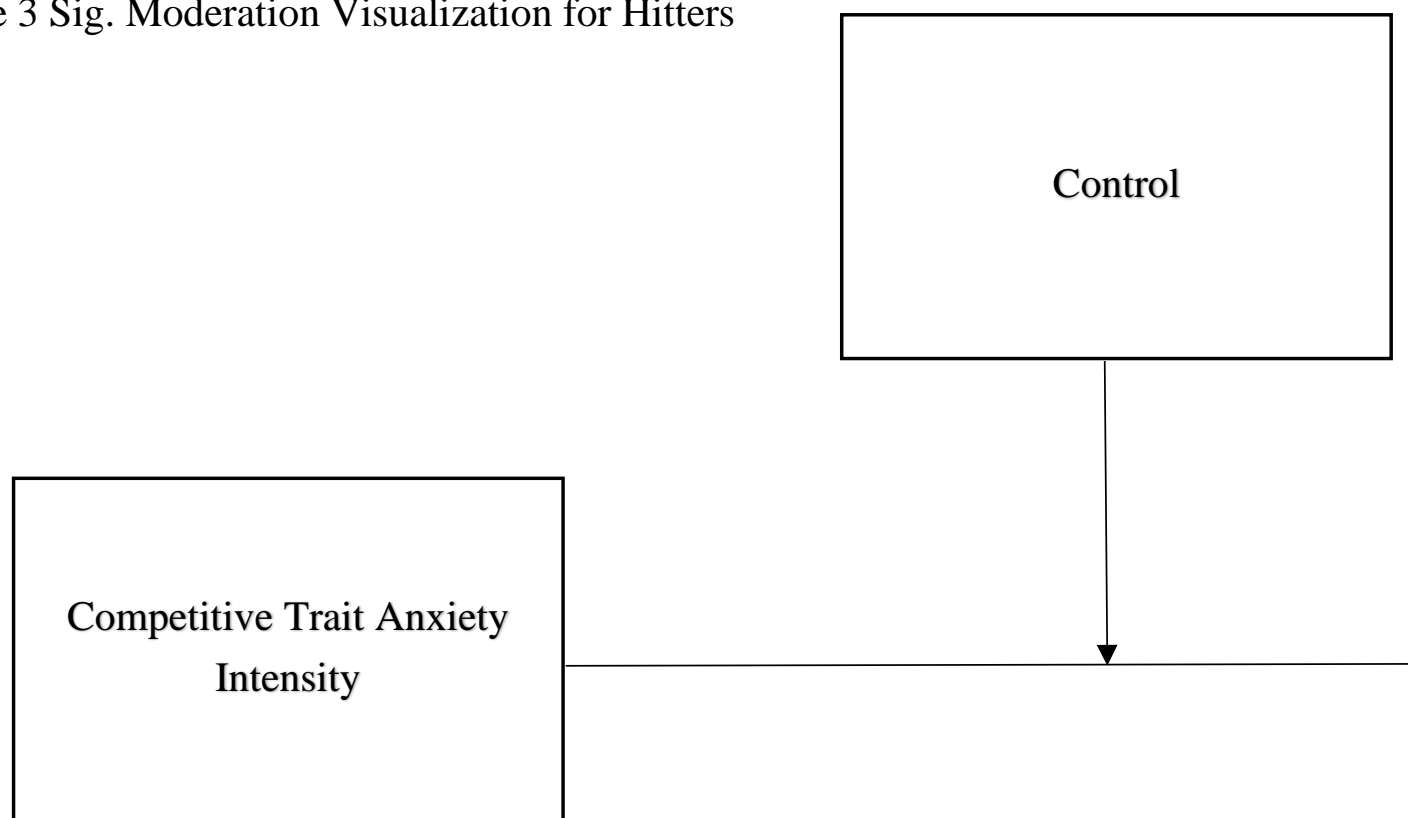

Hitter's Objective Performance Statistics 


\section{Appendix A: List of Hitting and Pitching Statistics and Formulas}

\section{Hitting Statistics}

On-Base Percentage Plus Slugging (OPS) is the hitters' on-base percentage added to their slugging percentage. Both of these statistics are listed as commonly distributed statistics by the team and are included in one number to combine how well a hitter reaches base and how well they can hit for power and average. On-base percentage is calculated by the number of times a batter reaches base per plate appearance and these include hits, walks, hit by pitches but do not include errors, times reached on a fielder's choice, dropped third strikes, or sacrifice bunts. Slugging percentage is calculated using the following equation:

$$
\underline{(1 \mathrm{~B}+(2 \mathrm{~B}) \times 2+(3 \mathrm{~B}) \times 3+(\mathrm{HR}) \times 4)}
$$

$\mathrm{AB}$

Weighted On-Base Average (wOBA) attempts to weight hits differently than OPS. Each hit is not worth the same and in OPS, it is assumed that a double is worth two times the amount of a single. This statistic allows hits or times on-base to be weighted differently and is a measure of a hitter's overall offensive value. wOBA can be calculated using the following equation:

$$
\frac{.69 \times(\mathrm{uBB})+.72 \times(\mathrm{HBP})+.89 \times(1 \mathrm{~B})+1.27 \times(2 \mathrm{~B})+1.62 \times(3 \mathrm{~B})+2.10 \times(\mathrm{HR})}{(\mathrm{AB})+(\mathrm{BB})-(\mathrm{IBB})+(\mathrm{SF})+(\mathrm{HBP})}
$$

Batting Average on Balls in Play (BABIP) calculates the rate at which a ball that is put in play by a hitter goes for a hit. This statistic does exclude home runs which are not technically in play but still do help the batter and the team. A ball in play is described as a plate appearance that does not end in a strikeout, walk, hit batter, catcher's interference, sacrifice bunt, or home run. Hitters have more control over their BABIP than pitcher's do and so this attempts to explain isolated individual performance while considering the defense, luck, and talent level. BABIP can be calculated using the following equation: 


\section{Pitching Statistics}

$$
(\mathrm{AB})-\frac{(\mathrm{H})-(\mathrm{HR})}{(\mathrm{K})-(\mathrm{HR})+(\mathrm{SF})}
$$

Walks Hits per Inning Pitched (WHIP) calculates the number of base runners allowed via hit or walks. This statistic attempts to identify exactly how many base runners a pitcher is preventing per inning. It is considered not to be the best statistic for pitchers as it treats all hits the same similar to OPS for hitters but it is a good starting place to understand what the pitcher is able to control. WHIP can be calculated using the following equation:

$$
\frac{(\text { Walks + Hits })}{\text { Innings }}
$$

Fielding Independent Pitching (FIP) is an estimate of pitcher's ERA based on results pitchers can control. FIP is a statistic that is based on outcomes that do not involve the defense such as strikeouts, walks, hit by pitches, and home runs allowed. It also takes out luck and sequencing of batters making it a more stable indicator of how a pitcher would have performed over a given period of time compared to ERA. It is well-regarded statistic that captures close to a pitcher's true performance. FIP can be calculated using the following equation:

$$
\frac{(13 \times(\mathrm{HR}))+3 \times((\mathrm{BB})+(\mathrm{HBP}))-(2 \times(\mathrm{K}))}{\text { Innings Pitched }}
$$

Left On-Base Percentage (LOB\%) calculates the percentage of base runners that a pitcher strands on base over the course of a season. It is calculated using the pitcher's actual hits, walks, and runs allowed. This statistic does not completely cover all situations as pitchers that strike out more batters have higher LOB\%. This statistic may be used to identify moments in games when pitchers are under pressure situations and are able to get out of it. LOB\% is calculated using the following equation:

$$
\frac{(\mathrm{H})+(\mathrm{BB})+(\mathrm{HBP})-(\mathrm{R})}{(\mathrm{H})+(\mathrm{BB})+(\mathrm{HBP})-(1.4 \times(\mathrm{HR}))}
$$




\section{Appendix B: Hardiness Questionnaire - PVS III-R}

Directions: Please answer the following 18 questions to the best of your ability, and as honestly as possible. This is important for report accuracy. There are no right or wrong answers.

$$
0=\text { Not at all True } \quad 1=\text { Somewhat True } \quad 2=\text { True } \quad 3=\text { Very True }
$$

$\begin{array}{lllllll}\text { 1. By working hard, you can always achieve your goal. } & & 0 & 1 & 2 & 3\end{array}$

2. I don't like to make changes in my everyday schedule. $\quad \begin{array}{lllll}0 & 1 & 2 & 3\end{array}$

3. I really look forward to my work. $\quad \begin{array}{lllll}0 & 1 & 2 & 3\end{array}$

4. I am not equipped to handle the unexpected problems of life. $\begin{array}{lllll}0 & 1 & 2 & 3\end{array}$

5. Most of what happens in life is just meant to be. $\quad \begin{array}{lllll}0 & 1 & 2 & 3\end{array}$

6. When I make plans, I'm certain I can make them work. $\quad \begin{array}{lllll}0 & 1 & 2 & 3\end{array}$

7. No matter how hard I try, my efforts usually accomplish little. $\begin{array}{lllll}0 & 1 & 2 & 3\end{array}$

8. I like a lot of variety in my work. $\quad \begin{array}{lllll}0 & 1 & 2 & 3\end{array}$

9. Most of the time, people listen carefully to what I have to say. $\begin{array}{lllll}0 & 1 & 2 & 3\end{array}$

10. Thinking of yourself as a free person just leads to frustration. $\begin{array}{llllll}0 & 1 & 2 & 3\end{array}$

11. Trying your best at what you do usually pays off in the end. $\begin{array}{lllll}0 & 1 & 2 & 3\end{array}$

$\begin{array}{lllll}\text { 12. My mistakes are usually very difficult to correct. } & 0 & 1 & 2 & 3\end{array}$

13. It bothers me when my daily routine gets interrupted. $\quad \begin{array}{llllll}0 & 1 & 2 & 3\end{array}$

14. I often wake up eager to take up life where it left off. $\quad \begin{array}{lllll}0 & 1 & 2 & 3\end{array}$

15. Lots of times, I really don't know my own mind. $\quad \begin{array}{lllll}0 & 1 & 2 & 3\end{array}$

16. Changes in routine provoke me to learn. $\quad \begin{array}{lllll}0 & 1 & 2 & 3\end{array}$

17. Most days, life is really interesting and exciting for me. $\quad \begin{array}{llllll}0 & 1 & 2 & 3\end{array}$

18. It's hard to imagine anyone getting excited about working. $\quad \begin{array}{llllll}0 & 1 & 2 & 3\end{array}$ 


\section{Appendix C: Confirmatory Factor Analyses Procedure for Updated PVS III-R Scale}

Initial reliability statistics, as estimated by Cronbach's alpha as a measure of internal consistency reliability, revealed that the PVS III-R scale for participants in this study demonstrated a Cronbach's alpha of 0.65 . In part due to this low reliability estimate, the PVS III$\mathrm{R}$ was further evaluated. To examine the original factor structure of the PVS III-R, confirmatory factor analysis (CFA) was conducted. Using CFA, model fit and item-by-factor loadings based on the originally proposed scale structure were first examined. Using previous recommendations for evaluating the fit of latent variable and CFA models (Hu \& Bentler, 1999), model fit was assessed using the root mean square error of approximation (RMSEA; value $\leq .06$ ), the comparative fit index (CFI; value $\geq .95)$, and the standardized root mean squared residual (SRMR; value $\leq .08)$. In addition, the traditional $\chi^{2} / d f$ ratio was used to complement evaluation of model fit; a criterion of 2.00 was used. Initial evaluation of the original structure of the PVSIII R was guided by a dissertation conducted by Paula Jameson (2012) in which the items and item-by-subscale structure were listed. The confirmatory factor analysis was conducted using Mplus (Version 8; Muthen \& Muthen, 2010, 2017). Given common issues associated with univariate and multivariate non-normality based on ordered item-level data, maximum likelihood estimation (MLM) with adjusted standard errors was used to evaluate items on the PVS III-R scale (Li, 2014).

A three-factor solution based on the same three sub-components included in previous work (Jameson, 2012) was first examined. Evaluation of the model did not reveal adequate fit, $\chi^{2}(132)=586.40, p<.05, \mathrm{RMSEA}=0.09, \mathrm{CFI}=0.50, \mathrm{SRMR}=0.12$; the ratio of $\chi^{2}$ to $d f$ was 4.44 (Table 8). Further examination of the initial model indicated several item loadings less than 0.30 in value with corresponding $R^{2}$ estimates falling below the lower-bound 0.10 criterion. In 
addition, several of the reverse-coded items - despite the use of recoding - demonstrated negative loadings onto specific factors. For example, a reverse-coded item "It's hard to imagine anyone getting excited about working," loaded negatively on the sub-scale of commitment when paired with other non-reverse-coded commitment sub-scale items.

Given this pattern of findings, modifications to the initial structure of the PVS-III R were made. Specifically, items that demonstrated loadings less than \pm 0.30 were first trimmed from the model. This model revision resulted in positively-worded items being retained to comprise the control and challenge factors. Next, remaining negatively-loaded items were trimmed from the model. This second modification resulted in positively-worded items being retained to comprise the commitment factor. Together, these modifications resulted in a trimmed, 9-item model in which three positively-worded items each loaded onto the control, commitment, and challenge factors. Evaluation of the revised model indicated adequate fit, $\chi^{2}(23)=39.27, p=.02$, $\mathrm{RMSEA}=0.04, \mathrm{CFI}=0.96, \mathrm{SRMR}=0.04$; the ratio of $\chi^{2}$ to $d f$ was 1.71 (Table 9). The majority $(77.78 \%)$ of standardized item loadings equaled or exceed 0.50 ; two loadings, contributing to the challenge factor, ranged from 0.33 to 0.37 . These findings of positively-worded items loading together reinforce recommendations to present items in positive language when designing and writing items when developing a scale (Kline, 2005).

To evaluate the contributions of these three revised factors to hardiness, a second-order CFA was then conducted whereby each of the three factors - control, commitment, and challenge - were specified to load onto a second-order hardiness factor (Bryne, 2013). The subscales demonstrated strong loadings onto the hardiness factor, with the control (0.95), commitment (0.98), and challenge (0.86) factors demonstrating standardized loadings that exceeded 0.80 (Figure 1). Among the three sub-scales of hardiness, challenge has previously 
been found to have the weakest loading of the three sub-scales and this CFA corroborates previous findings (Sheard \& Golby, 2006). Finally, to evaluate the reliability of the revised scale representing the PVS-III R, an estimate of composite reliability - appropriate for latent variable models as a less biased estimate of scale reliability - was calculated. The composite reliability estimate for the revised 9-item PVS-III R was 0.76 and additional reliability confirmation revealed a Cronbach's alpha of 0.73 . 


\section{Appendix D: Competitive Trait Anxiety Questionnaire - CTAI-2}

The effects of highly competitive sports can be powerful and very different among athletes. The inventory you are about to complete measures how you usually feel right before competition begins. Please complete the inventory as honestly as you can. Sometimes athletes feel they should not admit to any nervousness, anxiety, or worry they experience before competition because this is undesirable. Actually, these feelings are quite common, and to help us understand them we want you to share your feelings with us candidly. If you are usually worried about the competition or have butterflies or other feelings that you know are signs of anxiety, please indicate these feelings accurately on the inventory. Equally, if you usually feel calm and relaxed, indicate those feelings as accurately as you can. Your answers will not be shared with anyone. We will be looking only at group responses.

Directions: A number of statements that athletes have used to describe their feelings before competition are given on the following page. Read each statement and then circle the appropriate number to the right of the statement to indicate the intensity of how you usually feel right before competition. There are no right or wrong answers. Do not spend too much time on any one statement, but choose the answer which describes your usual feelings prior to competition.

For the interpretation section, please indicate whether the intensity of feeling that you usually experience has a positive or negative impact on your performance during competition.

\section{Scoring:}

Cognitive Anxiety

$>1,4,7,10,13,16,19,22,25$

Somatic Anxiety

$>2,5,8,11,14^{*}, 17,20,23,26$

Self-Confidence/Efficacy

$>3,6,9,12,15,18,21,24,27$

All of the scores are totaled for each factor. Meaning that you will

have both a total score for intensity and direction for each of the three factors.

*Item 14 is reverse scored for the somatic scale. 


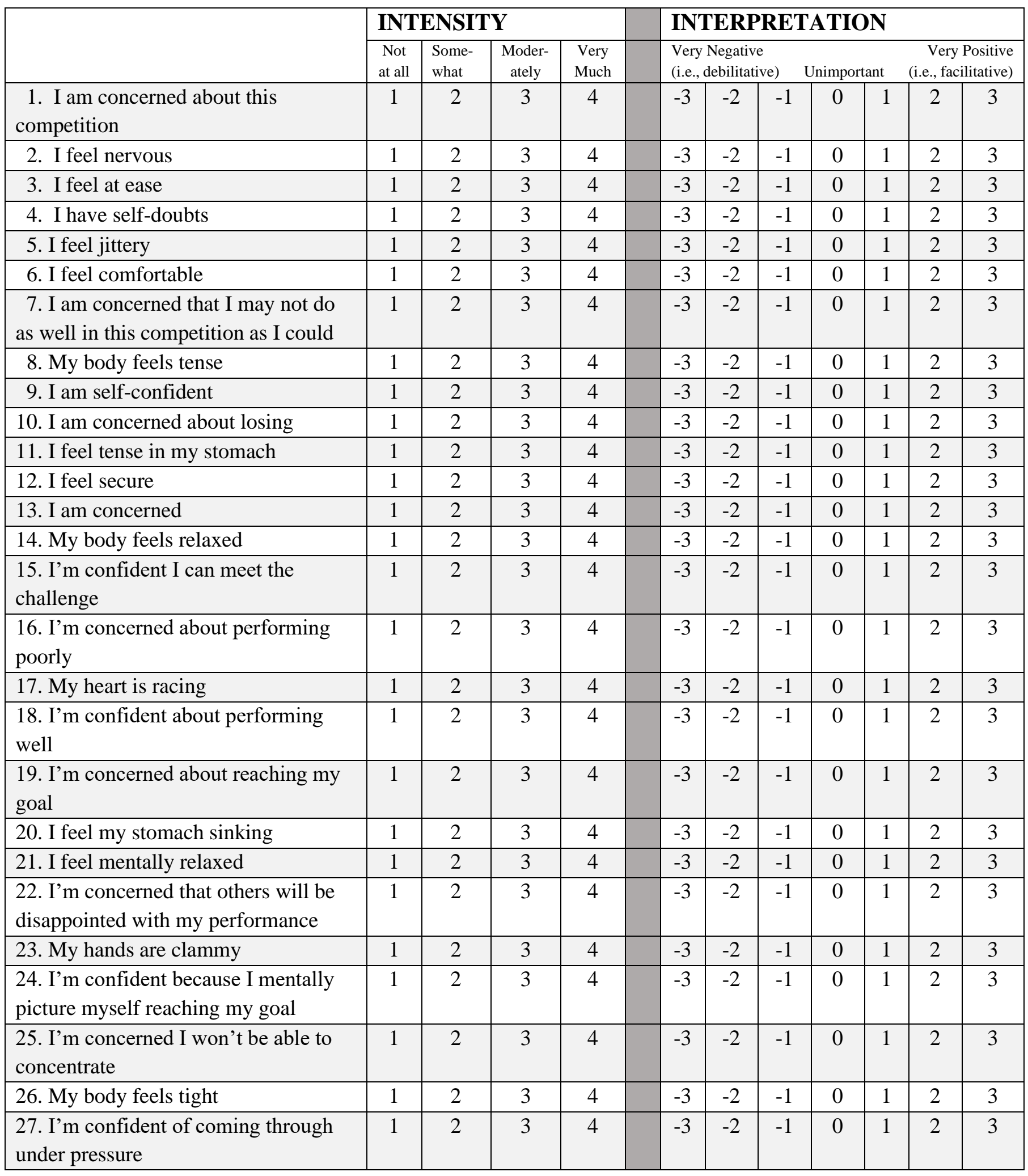




\section{Appendix E: Demographic Questionnaire}

Name:

Date:

Age:

College/University:

Position(s) played: Current Jersey Number:

Other NCAA D1 Sports Played (if none, leave blank):

Ethnicity:

O I am not Spanish, Hispanic, or Latino O Cuban

O Mexican O Cuban-American

O Mexican-American O Some other Spanish, Hispanic, or Latino group

O Chicano

O From multiple Spanish, Hispanic, or Latino group

O Puerto Rican

O Other:

Race:
O White
O Native Hawaiian or other Pacific Islander
O Black or African American
O From multiple races
O Asian
O Some other race
O American Indian or Alaska Native O Other:

Do you have previous/current experience working with a sport psychology professional (individually and/or in a team setting)?

$\mathrm{O} \quad$ Yes, both individually and in a team setting

O Yes, individually

$\mathrm{O} \quad$ Yes, in a team setting

O No

If yes, how long have you worked with a sport psychology professional individually? (Provide duration in months. Indicate 0 if you haven't worked with a sport psychology professional individually)

If yes, how long have you worked with a sport psychology professional in a team setting? (Provide duration in months. Indicate 0 if you haven't worked with a sport psychology professional in a team setting)

If yes, overall, how satisfied are you with the work you have done with a sport psychology professional?
O Extremely satisfied
O Somewhat dissatisfied
O Somewhat satisfied
O Extremely dissatisfied
O Neither satisfied nor dissatisfied 


\section{Appendix F: Extended Review of the Literature}

The study rate of personality in sport has increased dramatically after a hiatus in the field's research efforts (Allen et al., 2013). In the 1950s and 60s, sport personality was a widely popular field that captured researcher's imaginations with the idea that specific personality profiles existed that could predict successful athletic performance. Early researchers used inventories such as the Eysenck Personality Inventory (EPI; Eysenck \& Eysenck, 1964) or the 16 Personality Factor (16PF) questionnaire developed by Cattell (1965) to try and determine these personality profiles. Eventually, the field turned to the NEO, developed by McCrae and Costa (1985) that combined elements of both of the previous work of Cattell and Eysenck. The NEO measured five traits of personality, otherwise known by the acronym OCEAN, including openness, conscientiousness, extraversion, agreeableness, and neuroticism. Despite the NEO's improvements upon the $16 \mathrm{PF}$ and EPI, sport personality researchers still were not able to identify specific traits that would determine future athletic performance.

Steady research continued through the mid-1980s when researchers realized that despite the abundance of research that had been done on sport personality, there were no clear patterns of trait profiles that existed to predict performance (Morris, 2011). Some reasons for these inconclusive patterns could be explained by the limitations of global personality measures, restrictions of personality traits across temporal settings, and a reliance on personality as a predictor of sport performance (Allen et al., 2017). However, after a twenty-year hiatus, sportpersonality researchers have recently resumed interest in the field with a different approach that focuses on individual personality characteristics and state-type personality rather than a full profile of traits (Roberts \& Woodman, 2017). 
The revival of research within the sport personality field emphasizing individual personality characteristics demonstrates the still tantalizing possibility of forecasting athletic performance. Although the efforts to define specific personality traits across a generalized population have been inconclusive so far (Morris, 2011), the continued research in this field could give athletes, coaches, and consultants valuable information. Furthermore, certain individual personality characteristics have found to be dynamic and malleable over time (McAdams \& Olson, 2010; Roberts \& Woodman, 2017) and if practitioners understand how to foster specific personality characteristics, then there may be significant advantages to be gained in performance. Future sport-personality research could help practitioners understand and tailor individual interventions and practices to each player to encourage an athlete's development and improvement in sport performance (Allen \& Laborde, 2014).

The scope of this literature review will only include studies relating to individual personality characteristics. To understand the broader scope in personality research, please reference reviews by Allen et al. (2013) and Morris (2011). Sections will first focus on defining each individual personality characteristic of hardiness, mental toughness, resilience, and grit, giving overviews of each characteristics' measurements and questionnaires, and presenting recent and relevant studies of each construct. Then this literature review will include sections summarizing key findings across these constructs together. Finally, this literature review will include a conclusion and examination into the potential associations between these individual personality characteristics and objective performance.

\section{Individual Personality Characteristics Related to Competitiveness}

The shift from five-factor personality traits to individual personality characteristics largely stems from the ongoing debate in personality research regarding the difference between 
states and traits. Traits are known to be enduring, patterns of thought, feelings, or behavior that distinguish a person across temporal and physical settings while states are known to be thoughts, feelings, and behaviors in a certain moment in time (Laborde et al., 2019). The difference is that traits are much more stable and enduring across many moments while a state is a reflection of a particular setting or time. The initial research in sport personality was hoping to capture crosssituational trait profiles that could define athletes across all moments and settings. However, the unclear results of years of research has led to a larger emphasis on understanding individual's personality from state and cross-time trait standpoints (McAdams \& Olson, 2010).

In a mapping review, Laborde et al. (2019) helped inform further reviews and primary research with a review of the gaps in the field from ten different international sport psychology journals. In this review, researchers used a thematic analysis to map personality traits for sport performance onto its closest facet from the Big Five NEO. The 30 NEO-PI-R was used as a foundational framework because it captured fundamental components of human personality. The researchers identified sixty-four discrete traits and fifteen-higher order themes in which to categorize these discrete personality traits. Not all traits fit succinctly into a theme but most were matched up with an appropriate category.

One of the higher-order themes that the researchers identified was competitiveness. Within competitiveness, the thematic analysis used by the researchers identified grit, mental toughness, resilience, and hardiness as traits related to competitiveness. All of these traits were linked to the Big-Five trait of conscientiousness (Laborde et al., 2019). Conscientiousness had been previously linked to successful performance in collegiate athletes (Piedmont et al., 1999) and this link could be further supported with the exploration of grit, resilience, hardiness, and mental toughness' links to performance. 
As a result of this mapping study, Laborde et al. (2019) recommended that future research in the field attempt to conduct a research synthesis of specific themes to progress research in the sport personality field. A research synthesis of each thematic topic would benefit future researchers also interested in this area to help differentiate between the similar traits. The aim of this literature review will be to both conduct a research synthesis of the higher-order theme of competitiveness within sport personality research and to establish the basis for study between the individual personality characteristic of hardiness and performance in sport from an individualistic, interactionist, and theoretical basis.

\section{Hardiness}

Among the personality characteristics studied in sport, the concept of hardiness has come more into focus for researchers as it meets the criteria for a personality characteristic by having both a theoretical base and allowing for developmental research (Morris, 2011). Hardiness is defined as "a person's predisposition to be resistant to the harmful effects of stressors and effectively adapt and cope with a demanding environment," (Kobasa et al., 1982). The theoretical basis was developed by Kobasa (1979) in a landmark study where researchers investigated personality as a reason that different people facing stress would either become ill or avoid illness.

In the study, 161 executives from a telephone business company (i.e., Illinois Bell Telephone) were separated into two different groups that included those with high levels of stress and low illness $(n=86)$ or high levels of stress and high illness $(n=75)$. The participants were mostly male, 40 to 49 years old, married, and the researchers found that although both groups went through high stress, the high stress and low illness executives reported higher in hardiness and it was concluded that those individuals "had a stronger commitment to self, an attitude of 
vigorousness toward the environment, a sense of meaningfulness, and an internal locus of control" (Kobasa, 1979, p. 9). This study was one of the first of its kind to study the concept of hardiness with a proposed hardiness scale that measured challenge, control, and commitment.

As defined by Kobasa, control is "the belief that an individual can control or influence the events of their experience, commitment is the ability to feel deeply involved in or committed to the activities of their lives, and challenge is the anticipation of change as an exciting challenge for further development" (Kobasa, 1979, p. 3). Kobasa went on to further describe the hardiness subcomponents in the following ways. Control includes decisional and cognitive control, and coping skills. Commitment includes the belief system that helps minimize stressful life events and a recognition of one's distinctive values, goals, and priorities. Challenge requires the predisposition to be cognitively flexible to allow individuals to integrate and appraise the threat of new situations. These three elements help define the way that individuals can perceive or face stressful events or environments and develop their sense of hardiness to prevent illnesses or other maladaptive responses.

Hardiness Instruments. Hardiness is typically measured using the Personal Views Survey III-R (PVS III-R) which is in its third edition and is an 18-item scale which measures challenge, commitment, and control (Maddi et al., 2006). The Personal Views Survey initially started out as a scale that was tested by Kobasa (1979) but was further developed by Maddi (2002) to create an empirically validated scale. The original measure was collected from six different available scales that had relevance to commitment, control, and challenge. Initial challengers to the measure thought it lined up too closely with negative affectivity. This led to the development of the PVS-II (Maddi, 1997) and the PVS-III (Maddi \& Khoshaba, 2001) to fix 
this problem and only included questions that related specifically to hardiness (Maddi et al., 2006).

The most recent version of the PVS III-R was revised from fifty items to eighteen items to improve brevity when researchers furthered the construct validation process by testing the PVS III-R in four different studies. Across the four studies, Maddi et al. (2006), recruited samples of 1,239 students and adults, 128 college undergraduates, 148 college undergraduates, and 47 human resource services employees to complete both the PVS III and the PVS III-R to establish if the shortened version was measuring the same constructs of hardiness. The researchers found that across the four studies, the PVS III-R had an internal consistency coefficient alpha of $0.80,0.77,0.70,0.74$ respectively and no significance correlations were reported between the three subcomponents of hardiness. These studies further helped validate the construct of hardiness and the use of the PVS III-R as a shortened version of the PVS III which had already been frequently measured and used.

Hardiness has also been measured using the Dispositional Resilience Scale (DRS), and the Cognitive Hardiness Inventory (CHI). The Dispositional Resilience Scale was written by Bartone (1989) and has 45 items measure the three subscales of commitment, challenge, and control. Although it has the word resilience in its name, it has been referred to as a measurement of hardiness and generally attributes hardiness as a fixed trait (Windle et al., 2011). The Cognitive Hardiness Inventory has been used in the least among studies found in this review (Goss, 1994; Thomas et al., 2013) but was developed by Kenneth Nowack (1990). This scale was created from the three subcomponents of hardiness as found by Kobasa (1979). It demonstrated convergent validity with the original Kobasa hardiness scales and its internal reliability was 0.83 (Nowack, 1990). 
Among these questionnaires, the PVS III-R or a similar version was used by seven different studies found in this review and is the most established among the questionnaires. However, the DRS was also commonly used by four different studies found in this review, mostly from Europe and Australia while the CHI was only used twice in studies found in this review and is not commonly used anymore.

Hardiness Studies and Findings. The importance and potential of hardiness can be summed up in a meta-analysis, where Eschleman et al. (2010) concluded that hardiness is arguably one of the best predictors of well-being in general populations compared to other health-oriented dispositions such as self-esteem or locus of control. In a meta-analytic study, researchers included 180 studies involving hardiness and its antecedents and consequences to compare hardiness across studies from all domains. This included all studies that used the PVS III-R, DRS, and Cognitive Hardiness Scale. One finding from the study included that hardiness was positively correlated with job performance $(r=.17, \rho=.26, k=5, N=676)$ and school performance ( $r=.21, \rho=.23, k=3, N=623$ ), albeit moderately for both. The sub components of commitment and control both had similar results but challenge was not significantly associated with job performance $(r=.05, \rho=.10, k=4, N=451)$. Although these results do not specifically measure performance in sport, there are still other domains in which researchers have examined hardiness.

Hardiness has also been found to be a mediating or buffering factor for illnesses within a workplace setting. In a landmark study by Kobasa et al. (1982), the researcher recruited participants from a large utility company. The researchers used random selection across all management employees and questionnaires were sent out to 204 managers. Due to attrition and incomplete questionnaires, the final participant sample was 137 male, middle and upper-level 
employees. Participants answered questionnaires regarding stressful life events and illnesses, which was adapted from the Schedule of Life Events questionnaire, and regarding hardiness, which was the same composite questionnaire used in the original Kobasa (1979) study.

The researchers found that as hardiness increased, illnesses decreased $(F=19.83$, $p<0.001)$. The authors interpreted this finding to show that hardiness has a buffering or moderating effect upon stressful events which could lead to a decrease in illnesses. Although this study is older and only uses males in its participant sample, it was one of the first studies evaluating hardiness and well-being in a workplace setting. Future research further supported the mediating effects of hardiness on well-being in non-sport settings.

There has also been previous research examining hardiness in military training (Florian et al., 1995). In this study, researchers recruited 276 Israeli recruits, all 18 years of age, who were just beginning their compulsory service training for the Israeli Defense Forces. Participants filled out questionnaires on hardiness (PVS-III; 50 items), mental health (Mental Health Inventory), cognitive appraisal, and ways of coping before starting a four-month intensive basic combat training. Participants filled out questionnaires at two different times, once at the beginning and once at the end of training. Researchers were interested if hardiness acted as a stress-resistance resource within first-year cadets in military training

The researchers found that control and commitment were correlated higher $(r=.55)$ than challenge and commitment ( $r=.33)$ and challenge and control $(r=.27)$. The researchers used a LISREL program to represent goodness of fit. Commitment was positively associated with secondary appraisal $(r=.33)$, inversely related to threat appraisal $(r=-.31)$, and the use of distancing ( $r=-.16)$ and emotion-focused coping $(r=-.30)$. Researchers found that hardiness components helped individuals appraise combat training as less threatening, feel more capable of 
coping with it, and use more coping strategies. Also, patterns of appraisal and coping related to higher levels of hardiness and led to better mental health. The researchers also felt that hardiness components should be researched as separate constructs rather than one unified entity. This study was one of the first to evaluate hardiness levels in the military as a two-timepoint longitudinal design study but lacked a control group. Across these studies, hardiness was found to have mediating effects on well-being in work-place settings and coping abilities in military training.

Hardiness and Sport-Injuries. Within sport, there has been previous research specifically regarding sport-injury (Wadey et al., 2012a). In a study that monitored 694 participants $(M=19.17)$ over the span of two years, researchers followed up with 104 athletes who became injured. The athletes' injuries all happened only once during the two-year period and included fractures, dislocations, strains, and sprains. The amount of time lost from competition due to injury ranged from 14 to 504 days. Participants had an average of three years of experience in their sport and were a part of eight different team-sports and ten different individual-sports from recreational to international levels of competition. Participants filled out questionnaires regarding major life events, hardiness (DRS), coping strategies (Coping Orientation to Problems Experienced), and psychological responses. All participants filled out the DRS as a part of the initial pre-injury baseline questionnaires.

Researchers found that hardiness inversely correlated with injury occurrence, as a participant's hardiness score increases, their risk of injury decreases (Wald test $=32.922, p<.001$ ). Athletes who reported higher levels of hardiness experienced demanding athletic situations similarly to athletes who reported low levels of hardiness but appraised the situational demands as less stressful. This appraisal decreased the severity of the stress response and subsequent risk of injury. Individuals who reported higher levels of hardiness also transformed major life events 
from potentially debilitating experiences into opportunities for growth and development through appraisals, coping, and social support. More major life events could increase the risk of injury but athletes higher in hardiness might resolve the events they experience through these mechanisms and reduce their history of unresolved major life events, therefore lowering their risk of injury. This study is an influential study that gives good support for one of the possible utilities of hardiness in a sport-injury prevention setting by using a longitudinal design.

Other studies with samples of 10 (Wadey et al., 2012b), 121 (Ford et al., 2000), and 20 (Salim et al., 2016) participants have also examined the relationship between hardiness and sport-injury and seems to correlate well with injury prevalence and prevention.

Hardiness and Group Differences. Based on research on hardiness outside of sport, sport personality researchers started to examine if hardiness would also be a good predictor of wellbeing within the realm of sport. In a study by Sheard and Golby (2010), the researchers investigated differing levels of hardiness across various levels of competition. Participants included 1566 volunteers $(M=21.7$ years, range $=17-42$ years $)$ from sixteen different sports that competed at international, national, county, or club levels. Participants competed in contact team sports (field hockey, rugby league, rugby union, and soccer, $n=992$ ), contact individual sports (martial arts \& amateur boxing, $n=19$ ), non-contact team sports (basketball, cricket, netball, and volleyball, $n=157$ ), or non-contact individual sports (artistic roller-skating, canoeing/rowing/kayaking, equestrian, gymnastics/trampoline, racquet sports, swimming, and track and field, $n=398$ ). Participants completed the hardiness measure, PVS III-R and researchers collected the questionnaire data over an eight-year period from October 2000 to June 2008 during training environments of each athlete's sport. At the time of they filled out the measure, each performer was performing at the highest competitive level up to that point. 
The researchers analyzed the data using a MANCOVA multivariate analysis of covariance and found a significant effect for commitment between competition levels $(p<.001$, $\left.\eta_{p}^{2}=.05\right)$ which indicated that international competitors scored higher on commitment than national or club performers. There was also a significant effect for control $\left(p<.001, \eta_{p}^{2}=.04\right)$ but no significant difference for challenge $\left(p=.007, \eta_{p}^{2}=.01\right)$. This finding reinforces the idea that the hardiness components should be treated as separate entities rather than one large hardiness component all together.

This study helped inform the field that international competitors scored significantly higher than athletes at subordinate levels and national and county competitors scored higher than club performers. These findings reinforce that hardiness is a psychological characteristic that distinguishes elite-level sport performers from their sub-elite counterparts. Among sport performers, hardiness subcomponents explained five percent of variance in competitive standard by commitment, four percent by control, and one percent by challenge.

Although the previous study drew from a large variance of athletes from many different sports, other studies also examined hardiness differences by competition level within specific sports. Thomas et al. (2013) recruited male, elite, full-time professional motorcycle racers to examine if hardiness also differed by competition level. Participants were either from two different professional motorcycling races ( $n=16$ for each, $n=32$ total) or weekend club motorcycle racers $(n=31)$. The elite performers had ridden at an international level and scored points in at least one race during the competitive season. Participants completed the CHI, a 30item inventory based off the original Kobasa hardiness scales.

The researchers found that hardiness levels reported for all elite riders were significantly higher than weekend club riders (Cohen's $d=0.6$ ). There was also no significant difference 
between the two elite motorcycle groups but there was a significant difference between the top ten percent and bottom ten percent of the (Cohen's $d=2.3$ ). These results, again, help reinforce that hardiness can improve with skill level and performance. This study adds to the field by examining hardiness differences among competition level within the individual sport of motorcycle racing.

Hardiness has also been examined specifically in high-school female-athletes (Devin et al., 2015). Researchers recruited 269 female high school student athletes from Iran, 79 of which were from individual sports, including table tennis, track and field, swimming and badminton, and 190 of which were from team sports, including volleyball, basketball, and football. The researchers used a stratified sampling method to select participants from a larger pool of 900 female athletes playing at their highest competitive level. Participants completed questionnaires on hardiness (PVS III-R) and competitiveness (modified 28-item questionnaire).

Researchers found that individual sport female athletes $(r=0.553, p<.05)$ were significantly better than team sport athletes $(r=.435, p<.001)$ when reporting psychological hardiness and the three subcomponents of challenge, control, and commitment. The study adds to the field by identifying if there are differences between individual and team-sport athletes, but again, this approach is reflective of the type of research that was not successful at finding definitive results in initial personality research. The researchers did use the PVS III-R and a stratified sampling method but the sample is limited to female athletes only.

Hardiness and Mental Health. Another study that examined the interaction of hardiness and other factors contributing to performance was conducted by Goss in 1994. Goss examined the relationship between hardiness and mood disturbances in swimmers during overtraining. This study validates the work first done by Kobasa (1979) that found hardiness to have a moderating 
effect on illness and stress. Participants included 253 male and female swimmers from eight different universities and seven swimming programs. Participants filled out questionnaires related to hardiness $(\mathrm{CHI})$, mood states, coping behaviors, and social desirability. This study used two data collection time points with the first occurring during the first two weeks of the fall season and then repeated later during two seven-week intervals following the beginning of training. Similar training schedules allowed for similar data collection despite level differences.

Goss (1994) found that there was a significant relationship between age and hardiness $(r=.16, p<.01)$ and as age increased, so did hardiness. However, the amount of variance in the hardiness score accounted for by age was minimal $\left(r^{2}=.02, p<.01\right)$. There was, however, no significant difference between gender. The researcher also split the swimmers into two hardiness groups and used a $2 \times 2$ analysis of covariance, ANCOVA, to account for possible confounding effects due to initial differences and found that there was indeed a difference between the highhardiness and low-hardiness groups that existed at the outset of the season.

Goss also used a 2x3 Group x Time repeated measures MANOVA to show that as hardiness increased, maladaptive coping behaviors decreased while adaptive coping behaviors increased. There was also a negative relationship that as hardiness increased, mood disturbances decreased and those who reported higher in hardiness were not as prone to stress. Swimmers who reported higher in hardiness possessed fewer mood disturbances than nonhardy swimmers and were less tense, depressed, angry, fatigued, and confused (Goss, 1994). This study was one of the first studies after the conceptualization of hardiness to examine hardiness levels in athletes and paved the way for future researchers to examine the interaction between mood disturbances and hardiness and performance. Also, this is one of the few hardiness studies that uses the CHI instead of the PVS III-R. 
In a study that examined the effects of hardiness on anxiety interpretation, Hanton et al. (2013) recruited 510 collegiate and club sport performers $(M=20$ years, Range $=18-45$ years $)$ competing in 34 different sports ranging from county level to international competition. Researchers investigated the interaction of hardiness and trait anxiety interpretation on the competitive trait anxiety intensity response and the frequency and effectiveness of coping usage after a recent competitive situation. Participants filled out questionnaires relating to hardiness (DRS), self-confidence (Competitive Trait Anxiety-2 Self-Confidence Scale), coping strategies (Modified COPE) and sport anxiety (Modified Sport Anxiety Scale).

The researchers used two-way MANOVAs to analyze the interaction of hardiness and anxiety direction. They found significant main effects for hardiness $\left(n p^{2}=.1, p<0.001\right)$ and concluded that performers who reported higher levels of hardiness reported higher levels of selfconfidence and reported lower levels of worry intensity and somatic anxiety intensity. The researchers interpreted hardiness to be an important individual personality characteristic when examining the competitive trait anxiety response and hardiness as a facilitative interpretation of anxiety could be associated with effective coping. Individuals higher in hardiness can appraise situations as less threatening which leads to lower levels of anxiety. Coping strategies were most effective when individuals reported higher levels of hardiness and viewed the anxiety they are experiencing as being beneficial to performance.

The researchers proposed that future research should investigate a broader range of coping strategies as a function of hardiness and anxiety interpretation and incorporate a measure of performance within a study that considers hardiness and anxiety interpretation. This study helps add to the literature a study examining the interaction between hardiness and anxiety that could lead to the investigation of performance but lacks an objective performance measure itself. 
These two studies together address the relationships in which hardiness has been examined in the field thus far. Hardiness has commonly been used in conversation with characteristics such as mental toughness. The following section will attempt to define mental toughness, introduce instruments used to measure mental toughness, and examine studies related to mental toughness.

\section{Mental Toughness}

Mental toughness is a highly popular term used in sport psychology research, but the definition of mental toughness is still changing and a steadfast operational definition has not yet been achieved (Coulter et al., 2018). Again, the debate between whether the personality trait of mental toughness is a trait or state has come to the forefront of researchers. In a recent review of the present conception of mental toughness, Gucciardi attempted to define mental toughness as "a state-like psychological resource that is purposeful, flexible, and efficient in nature of the enactment and maintenance of goal-directed pursuits" (Gucciardi, 2017, p. 11).

Previous definitions of mental toughness had focused on the 4 C's model, which includes the three aspects of hardiness, challenge, control, and commitment but adds on the fourth $\mathrm{C}$ of confidence. This approach has not been justified as a distinct concept from hardiness and because of the overlap, researchers of mental toughness are not certain if this is distinct from hardiness or an extension of hardiness (Gucciardi, 2017). More research and conceptualization is needed to resolve definitional issues of mental toughness as the concept draws much interest from researchers in the field but they do not seem to all be measuring the same construct.

Mental Toughness Instruments. There are a variety of scales and measurements for mental toughness but many of them reflect a specific definition of mental toughness and due to 
the uncertainty in construct, there is not one particular measure that has been found to be better than others. A few measures are outlined in this section.

The Psychological Performance Inventory (PPI) is a forty-two item scale that measures seven different subscales of self-confidence, negative energy control, attention control, visualization and imagery control, motivation, positive energy, and attitude control (Loehr 1986). The Psychological Performance Inventory-Alternative (PPI-A) (Golby et al., 2007) measures determination, self-belief, positive cognition, visualization and is an extension of the original PPI. The Mental Toughness Questionnaire (MTQ48) functions from the basis of the 4C's model which includes the three aspects of hardiness, challenge, control, and commitment, and adds on the fourth C of confidence (Crust \& Clough, 2005). But this questionnaire draws a lot upon hardiness and is not necessarily shown to be different from hardiness yet and could just be an extension of hardiness. Finally, the Sport Mental Toughness Questionnaire (SMTQ) (Sheard et al., 2009) measures confidence, constancy, and control.

Across all the questionnaires, the PPI is the most commonly used and there are certain sub-constructs that are measured across them all but again, there are still other instruments that measure different elements of mental toughness and none have come to any definite conclusions. Future research could help define and validate certain scales to measure mental toughness.

Mental Toughness Studies and Findings. In a study to test the construct of mental toughness, Gucciardi et al. (2015) conducted five different studies to examine mental toughness. First, they reviewed the definitions of mental toughness that had already been offered in previous research of which they found five different definitions. They defined mental toughness as "a personal capacity to produce consistently high levels of subjective or objective performance despite everyday challenges and stressors as well as significant adversities" (Gucciardi et al., 
2015, p. 28). Their definition of mental toughness differed from resilience and emphasized elements of thriving after adversity while resilience just emphasizes returning to the original state. In their definition, mental toughness means bouncing back after adversity to a superior level of functioning.

In the first study the researchers conducted, they recruited thirty academic experts to be a part of focus groups to define the key dimensions of mental toughness. These experts included researchers, students, athletes, coaches, and businesspeople from four different countries. The researchers developed seventy different items assessing the conceptualization of mental toughness which eventually got cut down to sixty-one items. In the second study, researchers recruited three independent samples of students, athletes, and employees to further test their hypothesis of mental toughness as a multidimensional concept. The researchers found that mental toughness fit better into a unidimensional concept that measured perceived stress, performance, goal attainment, and thriving rather than a multidimensional construct such as the four C's (commitment, control, challenge, and confidence). This result led to the 8-item MTI that was an internally reliable score $(\rho=.86)$ across three independent samples.

In the third study, researchers recruited participants using a snowball sampling approach that included 497 employees from different working organizations in Australia. Participants filled out questionnaires regarding mental toughness (MTI) and perceived stress (Perceived Stress Scale) which were measured together against performance of the participant's workplace as assessed by their supervisor. Although this measure of performance may have been a subjective way to assess performance, the researchers found an indirect effect between mental toughness and performance through distress and coping (standardized indirect effect estimate $=$ 
$.24, p<.001)$. The authors claim that this is one of the first levels of support for higher levels of performance being directly associated with self-reported mental toughness.

In the fourth study, researchers recruited 203 undergraduate students. The participants filled out an eight-item MTI, six-item thriving scale, and psychological health questionnaire. The researchers found that mental toughness is important when understanding goal progress, thriving, and psychological health within a person. In the fifth and final study, researchers tested against the common multidimensional concept of hardiness (4 C's) and included some measurement of hardiness. Participants included 115 Australian male candidates aged twenty to forty-one years old ( $M=27.16$ years) and filled out questionnaires regarding mental toughness (MTI), hardiness (DRS), and self-efficacy (New General Self-Efficacy Scale). The researchers found that mental toughness was positively correlated with commitment $(r=.42)$, control $(r=.44)$, and challenge $(r=.34)$. Mental toughness also significantly predicted the performance outcome $(\beta=1.25$, $p<.05)$. These results support findings from study three with employees in supervisor-rated performance scales and used the completion of a rigorous military selection test as a measure of performance.

This conglomeration of studies helped contribute to the dimensionality of mental toughness and the authors recommended that mental toughness be considered as a unidimensional construct and not a multidimensional construct as commonly conceptualized by the 4 C's (Crust \& Clough, 2002). Some drawbacks of these studies were that in the two studies that measured performance, both did not measure mental toughness in a population of athletes. Again, supervisor-ratings in the third study seemed to be a rather subjective way to measure performance. Also, the fifth study used the DRS and not the PVS III-R as a measure of hardiness. Finally, the authors recommended that mental toughness should be considered "a 
state-like concept that can both vary and have enduring properties across situations and time" (Gucciardi et al., 2014, p. 41).

Overall, these studies contributes to the operational definition of mental toughness and adds some clarity to the dimensionality and traitness of mental toughness. Unfortunately, the participants in this study were mostly non-athletes and the two measures of performance were both not in a sport setting and one was a subjective measure of performance. Future research would help identify and further operationalize mental toughness and the scale that would measure it best.

\section{Resilience}

Broadly defined, resilience can be defined as "the capacity to maintain stable functioning and to undergo adaptation in the face of significant adversity" (Secades et al., 2016). Resilience necessitates the presence of adversity and resilience is then the positive adaptation after the moment of adversity. Within sport, there are some definitional and conceptual ambiguities that have limited the ability to research resilience in sport (Galli \& Gonzalez, 2015). There are many measures of resilience but due to the large amount of measures, there is not a systematic way to identify similar traits and the operationalization of resilience has been slowed. Much of the literature on resilience has come from other domains such as public health and education but there has been literature that supports that resilience is unique to the setting (Luthar et al., 2000). Therefore, future research has recommended resilience to be studied exclusively in sport domains.

Resilience Instruments. Researchers have used over nineteen different resilience scales and due to the abundance of resilience measures, there is not one specific questionnaire that has been found to be the most used measure. However, in a review of all the measures of resilience 
scales, the Connor-Davidson Resilience Scale, the Resilience Scale for Adults, and the Brief Resilience Scale are the most valid and reliable (Windle et al., 2011).

The Connor-Davidson Resilience Scale (CD-RISC; Connor \& Davidson, 2003) is a twenty-five item questionnaire that measures the five factors of personal competence, strengthening effects of stress, acceptance of change, control, and spiritual influences. The CDRISC also has a shorter ten-item version and both are measured on a five-point Likert scale. Although the questionnaire is one of the only resilience questionnaires to have been tested with athletes (Galli \& Gonzalez, 2015), it still could benefit from more theoretical clarification as it was rather limited in the attributes of resilience during its conception (Windle et al., 2011).

The Resilience Scale for Adults (RSA; Friborg et al., 2003) is a thirty-seven item questionnaire that examines protective factors that facilitate adaptation to five psychosocial adversities. These adversities include personal competence, social competence, family coherence, social support, and personal structure.

The Brief Resilience Scale (BRS; Smith et al., 2008) is a six-item scale that measures the ability to bounce back or recover from stress. It is commonly used as an outcome measure in the context of stress but no empirical validation of the data reduction is reported (Windle et al., 2011).

The Resilience Scale (Wagnild \& Young, 1993) includes twenty-five items on a sevenpoint scale and scores higher than 145 are considered high resilience, scores between 121 and 145 indicate moderate resilience, and scores of 120 or below are labeled low resilience. This scale has been identified to be applicable with a wide range of populations including adolescents, younger and older adults. 
The three initial measures all were developed for use with adult populations and not with younger children or adolescents. The Resilience Scale may have the most range of participants that it can measure resilience in. The large amount of resilience scales also is reflective of the uncertainty of researchers about a conceptualized definition for resilience.

Resilience Studies and Findings. In a review of resilience and sport performers, authors defined resilience within a sport setting as "the role of mental processes and behavior in promoting personal assets and protecting an individual from the potential negative effect of stressors." (Sarkar \& Fletcher, 2014, p. 1419). In this review, the authors focused specifically on sport domains and identified four main adversities that athletes experience, being injuries, performance slumps, illnesses, and career transitions. They also reviewed the different types of stressors that athletes and fit them into three categories, competitive stressors, organizational stressors, and personal stressors. The researchers were also able to identify protective factors that helped athletes cope with risk factors. The authors acknowledge that their definition of resilience adds to the conceptual construct of resilience that is still being defined within the sport context and hopes to add clarity to the operationalization of resilience within sport.

In another review a year later, Galli and Gonzalez (2015) summarized the current literature containing resilience in sport. This study covered seven different studies which included both qualitative and experimental-type designs. The variety of definitions of resilience all center around the two concepts of adversity and positive adaptation after adversity. While in other settings, adversity is clear, athletes might not always consider a performance failure as adverse which leads to questions about how often resilience can be identified in athletic performance. The authors recommend future work conceptualizing a single definition of 
resilience within sport and developing sport-specific measures that would reliably measure resilience and performance in sport settings.

In a specific study, Secades et al. (2016) conducted a study examining the differences between resilience and coping. They defined resilience as how an event is appraised and influences the stress process at multiple stages after the initial stress while coping was defined as the strategies employed following the initial appraisal of a stressful encounter (Secades et al., 2016). Participants included 235 Spanish athletes $(M=20.7$ years, Range $=15-35$ years $)$ from different individual (gymnastics, athletics, cycling, triathlon) and team sports (soccer, handball, volleyball, rugby) and a variety of regional, national, or international levels. The participants filled out questionnaires at two different time points, once right before the last competition of the season and once after the end of the most important competition in the season. The scales included questionnaires regarding coping and resilience (Resilience Scale).

The investigators used a 3x2 MANCOVA and found that the participant's scores on resilience did not significantly differ between the two timepoints. The authors did find that resilience correlated positively with task-oriented coping $(r=.35, p<.01)$ however, it was a moderate correlation. The authors drew the conclusion that high resilience qualities associated with coping strategies contribute more effectively by adapting to challenges or failures in athletics. Overall, this study adds to the resilience literature and its interplay with coping skills. The results included some moderate correlations and did not measure any elements of athletic performance. Also, participants ranged across competition levels that might have skewed some abilities to cope or display resiliency with more opportunities to fail at higher levels. 


\section{Grit}

Grit was conceptualized and defined by Duckworth et al. (2007) as perseverance and passion for long-term goals and the ability to approach achievement like a marathon. Duckworth and colleagues drew upon the Big-Five personality trait of conscientiousness to frame grit and individuals who have higher levels of grit emphasize long-term goals over short-term goals. Grit differs from a need for achievement and has distinct dependability aspects from self-control.

Grit Instruments. During the development of the grit scale, Duckworth et al. (2007) used four criteria while evaluating previous measures in the literature to see if there was already a valid measure of grit. These criteria included evidence of psychometric soundness, face validity for adolescents and adults pursuing goals in a variety of domains, low likelihood of ceiling effects in high-achieving populations and a precise fit with the construct of grit (Duckworth et al., 2009). Many measures did not meet all four of these criteria and so they created a self-report questionnaire called the grit scale which started out with 27 items and has been narrowed down to a twelve-item scale and an eight-item scale.

During the development of the grit scale, the researchers expected grit to be associated with conscientiousness, self-control and IQ in relation to high achievement. They used a crosssectional study to validate the self-report measure of grit in a sample of 1,545 participants aged 25 and older. Their procedure included the use of a public website that invited all users to answer this survey. They survey reflected items that did not specifically reflect a specific life domains and had a high internal consistency $(\alpha=.85)$ which supported the factors of consistency of interests and perseverance of effort. The Grit Scale (12-item scale) and the Short-Grit Scale (8item scale) are the two main scales. 
Grit Studies and Findings. In the initial study, Duckworth et al. (2007) conducted various studies to conceptualize their understanding of grit. The first study that the researchers conducted was a cross-sectional study to validate a self-report measure of grit. They expected older adults to report higher scores of grit than younger individuals and were interested if grit improves with age. The researchers used a public website to distribute the survey and ended up with 1,545 participants aged twenty-five and older. The questionnaire began with twenty-seven items and items were written to not specifically reflect a particular life domain. The results from the study helped reduce the scale down to 17 items and then further down to 12 items. The scale reflected high internal consistency $(\alpha=.85)$ and supported the sub-concepts of grit, consistency of interests and perseverance of effort. The researchers found a significant difference in grit for both education $\left(p<.001, \eta_{p}^{2}=.05\right)$ and age $\left(p<.001, \eta_{p}^{2}=.03\right)$.

The second study used a revised online survey that was based off of the first study and recruited 706 more participants $(M=45,80 \%$ women, $20 \%$ men $)$ to fill out the same survey but also complete the Big Five Inventory. The researchers found that grit related to conscientiousness more closely than any of the other Big Five traits $(r=.77, p<.001)$. Grit remained predictable by education and age even when all five of the big five factors were added to the covariance model and was also highest among the 65 years and older group and lowest among the 25-34 year-old group, which supports their previous hypothesis that grit increases with age.

In the third study, the researchers were interested if grit was associated with cumulative GPAs and SAT scores among high achievers. Participants included 139 undergraduate students (69\% women, 31\% men) majoring in psychology at the University of Pennsylvania. The researchers found that grit scores were correlated with higher GPAs $(r=.25, p<.01)$ but lower 
SAT Scores $(r=-.20, p<.03)$. The researchers attributed the difference in scores to less intelligent individuals having to work harder and with more determination to compensate for their lack of intelligence. This particular finding could also be explained by the difference between high school-level acceptance tests compared to GPAs that are accumulated over time in college. The pressure to take one particular test in high school to enter college could carry much more pressure and less ability to demonstrate grit compared to a semester-long grade that has many opportunities to be improved upon. Also, similar to the previous finding of grit improving with age, that could just be explained by older students' scores. These studies together offer some initial conceptualization of grit and how it could be used and studied within academic settings.

In a meta-analytic review of studies involving grit and performance, Crede et al. (2017) challenged the assumptions made in Duckworth and colleague's (2007) original argument for grit. The authors reviewed a series of studies that tried to replicate Duckworth's original findings and only one out of six following studies were able to replicate those findings especially in the realm of academic success. The authors also pointed out that there might have been a misinterpretation by Duckworth and colleagues when confusing "odds ratios with probabilities in their discussion of logistic regression results." This may have led to "incorrect inferences about the size of observed effects." Finally, the authors also challenge the assumption that conscientiousness and grit are completely separate constructs. At least three different since the conceptualization of grit have reported a correlation of $\mathrm{p}=.92$ or higher between conscientiousness and grit which has led some to suggest that grit should be a facet of conscientiousness (MacCann \& Roberts, 2010). The researchers included 73 different studies in their meta-analysis that recruited over 66,000 individuals across all the studies. 
The results from this meta-analysis indicate that there may be some assumptions about grit that need to be further explored. The concept of grit includes two facets of perseverance and consistency that are assumed to be sub-constructs of grit. But researchers found that perseverance is a better predictor of performance than consistency or overall grit and recommended that perseverance be measured distinctly from consistency. Also, in the metaanalysis, most studies that measured performance, measured academic or military performance and very few measured athletic performance. Finally, the researchers found that across all the studies, grit had a strong correlation with conscientiousness $(p=.84)$ and the researchers concluded that grit may be a repackaging of conscientiousness or an element of either perseverance or consistency separately but not together.

There were some positive findings to propel the grit literature forward as grit was a construct that predicted retention particularly well which does support one of the studies from Duckworth and colleague's (2007) initial study. Also, the sub-component of perseverance of effort did predict grade increases in academic settings better than overall grit and could be an area to focus on. Future research recommends the revisiting of grit construct and refinement of grit scales and measurements. Although this study does not specifically address athletic performance, some conclusions can still be drawn from this review that the grit literature is not a completely developed construct that could be used to predict performance, whether it be within athletics or in academics. This meta-analysis limits the excitement that the public has propelled the use of grit in multiple settings and questions its validity in relation to performance. These findings have also been supported by other reviews of grit in the literature, specifically within the field of health professional education (Stoffel \& Cain, 2018). 


\section{Summary of Competitiveness Characteristics}

After examining in depth each of these individual personality characteristics, hardiness was chosen to be the focus of this literature review due to the validity of its constructs supported by the literature and its theoretical links to performance. The difficulties that researchers have faced regarding definitional and construct validity of mental toughness have led to multiple instruments that have not been validated to fully measure a true definition of mental toughness. This makes it difficult to establish clear relationships between mental toughness and objective performance despite the attempts of various researchers to make those connections.

Resilience, as a construct, has a narrower focus and limits the impact that resilience has been able to have on performance compared to a wide-construct such as hardiness (Martin et al., 2015). One of the main reasons it is narrower is that its definitional meaning requires that there be a moment of adversity in order to be considered resilience and therefore limits the generalizability of the concept. While research on resilience in other settings can identify true instances of adversity, adversity is not always defined similarly by all athletes. So, similar to mental toughness, resilience has not been fully validated within a sport domain and the wide variety of measures used to measure resilience has not led to a golden standard with which to effectively measure resilience (Windle et al., 2011).

Grit has recently become a newer construct within the competitiveness schema that has caught early attention, but research has shown some measurement overlap with conscientiousness and draws some questions to some of the researchers' initial findings (Crede et al., 2017) and therefore limits its ability to demonstrate fundamental differences. Future research is needed to validate the findings first found by Duckworth and colleagues (2007), but grit research is still in its infancy as a construct. Of these four constructs, hardiness has a 
fundamental backing from the literature with its definitional conceptualization and measurement and a wider-range of settings it can be applied to. Further research provided here demonstrates the links between these constructs and performance.

In a study that compared resilience, hardiness, and grit in wheelchair basketball athletes, Martin et al. (2015) found that hardiness was the best predictor of overall life satisfaction. Participants included 75 adult athletes (Age, $M=37$, Range $=19-55$ years old $)$ with all participants identifying as male except for one female participant. All participants were recruited from a wheelchair basketball league in Midwest America. Participants filled out questionnaires regarding grit (Short 8-item grit scale), hardiness (DRS), resilience (CD-RS), life satisfaction, and engagement (16-item Athlete Engagement Questionnaire). Researchers predicted that grit would significantly predict life satisfaction and sport engagement more than hardiness and resilience.

The researchers found that although there were some moderate correlations between grit, hardiness, and resilience, each of the questionnaires given appeared to be measuring unique constructs. Hardiness accounted for $22 \%$ and $26 \%$ of variance in sport engagement and life satisfaction respectively. Researchers interpreted that hardiness was more significantly correlated to life satisfaction than resilience or grit. Hardiness, which is a more broadly defined type of personality disposition, was more strongly linked to life satisfaction than the narrowly defined construct of resilience. Grit had no role beyond any variance it might share with resilience and hardiness in promoting life satisfaction but did have eight percent more variance than hardiness and resilience combined on sport engagement. Hardiness was no correlated to sport engagement and resilience was moderately correlated to both life satisfaction and sport engagement. 
Overall this study helped distinguish hardiness from resilience and grit and helped show that hardiness is related to life satisfaction. It also helped identify that among the different questionnaires, measurements of the constructs were similar, but still each construct was measuring a unique personality characteristic. However, grit was measured with DRS and not PVS III-R. Although the population that was sampled were athletes, it was still a specific population that does not allow for generalization of results and did not relate to measures of performance.

Mental toughness and hardiness are two personality characteristics that have common overlap. Golby and Sheard (2004) attempted to identify differences in rugby league athletes. The researchers were curious how professional rugby players at differing levels of competition were in both mental toughness and hardiness. Participants included 115 professional rugby footballers from the top levels of Great Britain rugby league, which included international, super league, and division one playing standards. Participants answered questionnaires regarding hardiness (PVS III-R) and mental toughness (Psychological Performance Inventory) and the questionnaires were administered and counter-balanced.

The researchers found that performers playing at the top level, reported higher among control, commitment, and challenge compared to those in lower levels. The researchers used MANOVAs, ANOVAs, and Wilks's Lambdas to calculate that commitment $\left(p<.001, \eta_{p}^{2}=.46\right)$, control $\left(p<.001, \eta_{p}^{2}=.19\right)$ and challenge $\left(p<.001, \eta_{p}^{2}=.3\right)$ were all significant when compared to competition level. While all of hardiness was found to be significant, only two out of the seven subscales of mental toughness, negative energy control and attention control, were found to be significant. 
Researchers also discovered that the hardiness subconstructs of commitment, control, and challenge accounted for $46 \%, 35 \%$, and $19 \%$ respectively, of the variance in playing level. The mental toughness subcomponents of negative energy control and attention control were only able to account for $9 \%$ and $6 \%$ of the variance. This study adds to the field by reinforcing the relationship between athletes at higher levels of competition reporting higher levels of hardiness. But the study also found that hardiness, as a construct, had more explanatory ability than mental toughness did. This result could be explained by the measure that was chosen to quantify mental toughness (PPI) but this does give good support for the use of PVS III-R with athletes. The questionnaires were counterbalanced but lacked a performance measure although that was also mentioned as a future research direction. This study gives more support to using hardiness to explain sporting level differences than mental toughness.

These studies help illuminate the usefulness of hardiness measures and their possible validity compared to other commonly thought-of competitiveness constructs like hardiness, mental toughness, and resiliency. The following sections will review studies that have examined the relationships between individual competitiveness characteristics in both sport and non-sport settings and also studies that have examined multiple competitiveness characteristics at once in both sport and non-sport settings.

\section{Individual Competitiveness Characteristics and Objective Performance in Sport Settings}

To illuminate links between individual personality characteristics and objective performance, some studies have attempted to examine how personality characteristics interact with objective performance both in non-sport and sport settings.

The second half of the Duckworth et al. (2007) initial study focuses outside of the realm of sport investigating the correlation between multiple individual personality characteristics and 
performance. This study examined the effect of the individual characteristic of grit on performance in various non-sport settings. The fourth study was conducted at West Point Military Academy and performance was measured with a Whole Candidate Score (WCS). The researchers attempted to predict retention from the first summer and academic GPA to one year later and predicted that grit would correlate better than self-control to retention. The participants were 1218 freshman cadets in the USMA West Point academy, and they filled out questionnaires regarding grit (Grit Scale), self-control. The researchers used WCS, retention, and military performance scores as dependent variables. They found that grit was not related to the WCS $(r=.02, n s)$, SAT Score $(r=.05, n s)$, high school class rank $(r=-.04, n s)$, leadership potential score $(r=.05, n s)$, or physical aptitude exam $(r=.01, n s)$. Grit did predict completion of the military training program $(\beta=.48, p<.001)$ better than self-control $(\beta=.41, p<.01)$. This study showed that grit was a predictor for retention in military first-year cadets.

In the fifth study, the researchers recruited 1308 cadets from West Point Academy four years later to complete questionnaires regarding grit, and conscientiousness (9-item subscale of the BFI). They used WCS and retention scores again as dependent variables. The investigators used a binary logistic regression model and found that WCS was related to conscientiousness but not to grit. Also, summer retention predicted grit $(\beta=.31, p<.02)$ better than conscientiousness or WCS. These findings support the previous finding at West Point but also tried to differentiate grit from conscientiousness.

In the final study of the series, the researchers investigated grit within an academic performance setting. Participants included 175 participants (Range $=7-15$ years, 48\% girls, 52\% boys) out of 273 finalists for a National spelling bee in Washington D.C. The researchers used a verbal IQ test to measure verbal fluency and these tests were administered either on the phone, 
before competition, or following the competition. Participants filled out the grit scale, selfcontrol (BSCS), and a Verbal IQ scale (WISC-III Similarities subtest correlates with verbal IQ and full-scale IQ). The researchers also collected data on study time, number of rounds before elimination and how many prior competitions they had been in. The performance measure was the final round reached and prior competitions while study time was used as a mediator to the final round predictability of grit. The researchers found that grit was a significant predictor of final round reached $(\beta=.28, p<.001)$. The authors interpreted this finding to suggest that children who work harder and longer perform better. But as discussed in a previous review, the results interpreted by Duckworth and colleagues could also have misinterpreted certain findings (Crede et al., 2017). These last three studies from Duckworth and colleague's initial grit study provide examples of objective measures of success in non-sport settings. Although future research reviews have criticized the credibility of grit and the initial findings, this is still one of the landmark studies that examines the interactions between individual competitiveness characteristics and performance. Future research should evaluate how some of these relationships could be investigated in sport and attempt to replicate and reconcile these findings.

Previous research has started to examine the effectiveness of a psychological skills training on hardiness and mental toughness in swimmers. In a study, Sheard and Golby (2006) used a psychological skills training intervention to identify increases in objective performance for swimmers. They examined whether a mental skills intervention had a positive influence on swimming performance.

Participants included thirty-six swimmers $(M=13.9$ years, Range $=10-18$ years $)$, thirteen of which were boys and twenty-three of which were girls from three different national swimming clubs in the United Kingdom. They filled out questionnaires regarding positive psychological 
development, perceptions of success, mental toughness (Psychological Performance Inventory), hardiness (PVS III-R), self-esteem, self-efficacy, dispositional optimism, and positive and negative affectivity. These questionnaires were counterbalanced when collected and used in tandem with swimming performance as dependent variables. The participants all received the PST training, but researchers used a delayed control design and administered the PST to the first seventeen swimmers and after seven weeks, the remaining nineteen swimmers. Participants also kept subjective thoughts about the PST intervention in a logbook to give to the primary investigator and were used as social validation statements to triangulate the results.

The researchers used paired sample t-tests and found that twenty-three out of the thirtysix participants saw an improvement in their performance. In one event, 200m freestyle, there was a significant $\left(r_{p b}^{2}=2.40, p<.05\right)$ improvement in times across participants compared to before the intervention while two other events also had improvements, the $100 \mathrm{~m}$ breaststroke and the $200 \mathrm{~m}$ backstroke. Across the eighteen different positive psychological measures recorded with questionnaires, seventeen of them showed significant improvements with the exception being the challenge construct of hardiness. Challenge being the exception was explained by the authors to be due to the high initial scores in swimming and the swimmer's ability to increase that score was not as likely and could have been more debilitating to the swimmers than an opportunity to succeed. Commitment $(t=3.99, p<.01)$ and control $(t=1.98, p<.05)$ were both found to be significant as sub-components of hardiness. Mental toughness sub-components of the PPI were shown to have the highest increase in positive psychological development with selfconfidence $(t=5.71, p<.01)$, negative energy control $(t=5.56, p<.01)$, attention control $(t=3.70$, $p<.01)$, and visualization and imagery control $(t=3.94, p<.01)$. 
This study is unique and adds a great intervention study to both measure performance objectively in swimming times and identify increases in hardiness and mental toughness. The use of a psychological skill straining could be a method to model future interventions but due to the number of questionnaires, it is hard to determine which specific aspect of a swimmer's personality might account for it the increases in swimming time. Future research should attempt to follow this type of study to increase objective performance outcomes.

In another performance study within sport, Vealey and Perritt (2015) recruited 197 collegiate track and field athletes from Division I (77 athletes), II (55 athletes), and III (65 athletes) universities in the United States. Participants filled out questionnaire regarding hardiness (PVS-II), flow state (Dispositional Flow Scale), and optimism (Life Orientation Test Revised). The questionnaires were administered in noncompetitive situations, when coaches were not present, and counter-balanced to avoid ordering effects. Hardiness had been hypothesized to be linked to flow previously, but not empirically tested before this study so, researchers were investigating the relationship between hardiness and the frequency of flow experienced by athletes.

The researchers used multiple regression analyses to find that hardiness was significant ( $p<.001$, multiple $R=.53$ ) but, optimism was the most significant predictor of total flow (.4) and accounted for sixteen percent of variance. The subcomponents of control and commitment were also predictors of total flow, but only at six and five percent respectively and challenge did not significantly predict flow.

One of the limitations was that the researchers elected to use the PVS-II instead of the PVS III even though they were aware that it was available. The researchers mentioned in their future directions and limitations that this could have been one reason why there were no 
differences found between levels in this study. However, more studies are needed to verify this interaction of flow and personality characteristics.

One study that has investigated the interaction between objective performance and psychological constructs is a study by Zizzi et al. (2003) that examined the effect of emotional intelligence among college baseball players. Participants included 61 collegiate baseball players from Division I universities in the United States. The researchers used performance statistics from hitters and pitchers over a length of a season and minimum innings or plate appearances were used as inclusion criteria. The participants completed a 33-item measure of emotional intelligence the researchers analyzed the data using a one-way ANOVA.

The researchers found that hitting statistics did not seem to be significantly related to emotional intelligence and of the pitching statistics, only strikeouts had a significantly statistical relationship with emotional intelligence $(r(21)=.484, p<.05)$. This result was explained by the researchers to be correlated with the amount of control allowed in pitching and the reactionary nature of the act of hitting. This study supported a modest link between performance and emotional intelligence in pitchers $(r=.25$ to .48 , Cohen's $d=.54$ to 1.1$)$. Although this study does not specifically relate to personality, the methodological designs and construct could be replicated with the investigation of links between individual personality characteristics and performance.

\section{Future Research Directions}

After overviewing the current research on individual personality characteristics pertaining to competitiveness, future research directions should focus on continuing to conceptualize and operationalize personality characteristics for use in sport settings. All of the 
competitive characteristics covered in this review had some level of uncertainty regarding the definitional use of the concept.

Mental toughness has commonly been used in sport settings as a catchy word to motivate players but within the sport literature, there is uncertainty about its definitional construct and even more so, measures with which to measure it (Gucciardi, 2017). Future research would benefit from identifying if mental toughness as a state or trait personality characteristic and determining with which definition and which measures mental toughness would be best conceptualized as.

With resilience, researchers have conducted robust work on the effect of resilience after adversities outside of sport settings, but within sport, adversities are not clearly defined across all athletes and therefore leads to a lack of clarity with its definitional use in sport domains. Future research directions would benefit from clearly defining the different events that athletes consider adversities and using that information to further clarify resilience's conceptual use within sport settings. Also, future research would benefit from an established measure that would focus specifically on research with athletes as currently only one out of nineteen measures has been used with an athletic population (Windle et al., 2011).

Grit, being a newer construct, still would benefit from future research that validates its differentiation from the big-five trait of conscientiousness. Initially Duckworth and colleagues (2007) claimed discrete differences but further research and reviews have not corroborated those findings (Crede et al., 2017) and future research directions would benefit from further validation of the concept of grit as a distinct personality characteristic. But a lack of support could lead to the possible abandonment of grit as a separate validated individual personality construct. Grit 
research has also mainly focused on academic and military settings and more research would be beneficial in sport settings particularly with performance.

Finally, hardiness has been commonly measured as an entire construct altogether, but studies have proposed the possibility of separating the three sub-components of challenge, control, and commitment and treating those as their own constructs. Some researchers have also questioned the necessity for challenge to be a prerequisite or sub-component of hardiness as studies have shown that challenge is not always related to hardiness as well as commitment and control have shown to be (Sheard \& Golby, 2006). Future research would benefit from further examination of the necessary presence of challenge as a sub-component of grit and also comparisons between the DRS and the PVS III-R as the two main measures of hardiness.

Among the research found in this literature review, there was a scarcity of research examining the links between individual personality characteristics and objective performance. A couple studies (Sheard \& Golby, 2006; Vealey \& Perritt, 2015; Zizzi et al., 2003) examined relationships between individual personality characteristics and objective performances and others have examined this relationship with performance in military settings (Duckworth et al., 2007; Maddi et al., 2012) but future research would benefit from examinations of links between concepts like hardiness and objective performance within sport. Although some research has been done to examine this relationship, additional research would help validate this interaction.

Future research directions could also include studies including more state-like personality contexts. These studies would offer more accurate assessments of constructs within specific settings or domains and stray from trait generalizations that attempt to measure a global personality for sport and physical activity contexts. Future research could also extend to coaches and officials who also face adversities or need to perform to some extent and could benefit from 
higher levels of hardiness or resilience. Longitudinal research would be ideal to identify if characteristics like hardiness, which have been understood to develop or become established over time, present more commonly during certain developmental periods or after certain challenging or adverse events. If it can be shown that personality characteristics can be built up or developed, interventions for personality characteristics would be beneficial to see if it is possible to establish certain characteristics. Experimental research could also be beneficial to examine how certain characteristics could help or hurt performance in controlled settings which has been done in some previously similar studies (Geukes et al., 2017). There are many avenues still left to be explored, understood, and examined within the sport personality research.

\section{Conclusion}

Commonly in sport settings, words such as mental toughness, grit, and resilience are used as catch phrases or posted as bumper stickers to motivate or remind players to achieve a level of competitiveness. While the general fan, coaches, and athletes may throw around these words as they please, consultants and practitioners should be aware of what specifically each word conceptualizes and how to improve or instill those elements into their players. Due to the recent fascination with words such as grit and mental toughness in the sport psychology field, further research would benefit to identify the operational definitions of each word and how each word might be similar or different from each other. Especially, with the amount of research and funding that is now going toward programs that are focused on increasing grit or resilience, researchers should identify that the right constructs to use and the possible benefits or lack thereof that might result from these programs.

The purpose of this literature review was to provide both a research synthesis of the higher-order theme of competitiveness within sport personality research and to establish the basis 
for study between the individual personality characteristic of hardiness and performance in sport from an individualistic, interactionist, and theoretical basis. Due to the difficulties conceptualizing a mental toughness definition, the narrow construct of resilience, and the infancy and possible overlap of grit with conscientiousness, hardiness was determined to be the most viable construct of the four competitiveness constructs within the higher-order theme. Future research would benefit from continued attempts to operationally define grit, mental toughness, and resilience within sport contexts. Links between these characteristics and performance have been attempted in many studies outside of sport but few studies have examined this association within sport. The sport personality field would benefit from more investigations into the link between constructs like hardiness and objective performance.

Based on the need for continued research regarding personality characteristics, future research would also benefit from studies focusing on the development of characteristics like hardiness in a population of collegiate athletes. Longitudinal studies following athletes as they go through developmental stages would help identify if and when hardiness starts to develop in an athlete's career. This could give researchers insight about when and how to best instill interventions that could help athletes develop hardiness or other characteristics and help identify individuals who do or do not have hardiness as they go through transitions in their athletic career. Future research directions could also include experimental research examining if the presence of hardiness would help performance on controlled tasks and also qualitative studies examining the metacognition or self-awareness of athletes and how they perceive their personality affecting their sport performance. There are many directions still left to pursue within the sport personality field and this literature review hopefully has given further direction towards that cause. 